\title{
LA SENDA HACIA UN FEDERALISMO LEGISLATIVO DESDE UNOS PARLAMENTOS AUTONÓMICOS EN RED
}

\author{
REGIONAL PARLIAMENTS IN NETWORK: TOWARDS A LEGISLATIVE FEDERALISM?
}

\author{
Esther Seijas Villadangos \\ Universidad de León
}

Cómo citar / Nola aipatu: Seijas Villadangos, E. (2020). La senda hacia un federalismo legislativo desde unos parlamentos autonómicos en red. Legebiltzarreko Aldizkaria - LEGAL - Revista del Parlamento Vasco, (1): 94-129.

https://doi.org/10.47984/legal.2020.004

\section{RESUMEN}

Este trabajo estudia cómo la colaboración y cooperación interparlamentaria en un Estado descentralizado, en particular el Estado autonómico, ha contribuido y puede sustentar la conformación de un substrato sólido, real, de naturaleza federal, de la mano de lo que se denominará federalismo legislativo. El punto de partida será el estudio de cómo en España se ha afrontado dicha cooperación interparlamentaria, para -sin perder el referente de la irrupción de la cooperación interparlamentaria en un orden global- referenciar desde un punto de vista comparado, centrado en los casos estadounidense y canadiense, cómo los parlamentos en Estados federales han contribuido a sostener dicha estructura territorial desde su colaboración. El federalismo legislativo será un punto final en el que se compendiarán todas las enseñanzas de esa revisión casuística previa. Un análisis de los logros y retos de la cooperación interparlamentaria será la reflexión final sobre la concepción de la colaboración interparlamentaria territorial como garantía del pluralismo y como eslabón entre la unidad y la diversidad que sustenta la esencia de una federación.

\section{PALABRAS CLAVE}

Federalismo legislativo, cooperación interparlamentaria, soberanía parlamentaria, federalismo funcional, federalismo asimétrico. 


\section{ABSTRACT}

This essay studies how the interparliamentary collaboration and cooperation in a decentralized State, in particular the Autonomous State, has contributed to and can sustain the conformation of a solid, real substrate of a federal nature. The starting point will be the study of how such interparliamentary cooperation has been dealt with in Spain, in order to -without losing the benchmark of how interparliamentary cooperation has settled in a global order- refer, from a comparative point of view focused on the American and Canadian cases, how the parliaments in federal states have contributed to sustaining this territorial structure through their collaboration. Legislative federalism will be a final point, in which all the teachings of that previous case review will be summarized. An analysis of the achievements and challenges of interparliamentary cooperation will be the final reflection on the conception of interparliamentary territorial collaboration as a guarantee of pluralism and as a link between the unity and diversity that sustains the essence of a federation.

\section{KEYWORDS}

Legislative federalism, interparliamentary cooperation, parliamentary sovereignty, functional federalism, asymmetric federalism.

\section{LABURPENA}

Lan honek Estatu deszentralizatu batean, bereziki Estatu autonomikoan, parlamentuen arteko elkarlanak eta lankidetzak izaera federaleko substratu sendo baten eraketa nola lagundu duen eta nola sustengatu dezakeen aztertzen $\mathrm{du}$, federalismo legegile deituko diogunaren eskutik. Abiapuntua izango da aztertzea nola egin zaion aurre parlamentuen arteko lankidetza horri Espainian, ikuspegi konparatu batetik, Estatu Batuetako eta Kanadako kasuetan zentratuta, nola lagundu duten estatu federaletan dauden parlamentuek lurralde-egitura horri eusten, lankidetzan arituz, betiere, parlamentuen arteko lankidetza ordena orokor batean finkatu den erreferentea galdu gabe. Federalismo legegilea azken puntua izango da, eta bertan laburbilduko dira aurretiko berrikuspen kasuistiko horren irakaskuntza guztiak. Parlamentuen arteko lankidetzaren lorpenak eta erronkak aztertzea izango da lurraldeetako parlamentuen arteko lankidetza aniztasunaren berme gisa eta federazio baten funtsa sostengatzen duen batasunaren eta aniztasunaren arteko katebegi gisa ulertzeko moduari buruzko azken gogoeta.

\section{GAKO-HITZAK}

Federalismo legegilea, parlamentuen arteko lankidetza, subiranotasun parlamentarioa, federalismo funtzionala, federalismo asimetrikoa.

\section{SUMARIO}

I. LA COLABORACIÓN Y LA COOPERACIÓN INTERPARLAMENTARIA SUBESTATAL. 1. Cooperación orgánica interparlamentaria subestatal. 1.1. COPREPA. 1.2. CALRE. 2. La colaboración profesional. 2.1. AELPA. 2.2. ASEINPA. 3. Redes de cooperación interparlamentaria. 3.1. Red_Parlamenta. 3.2. Los parlamentos autonómicos en redes sociales. 4. Parlamentos digitalizados, abiertos, conectados a la sociedad y colaborativos. 5. La cooperación interparlamentaria subestatal como principio organizativo en la teoría constitucional. 6. A modo de ilustración, desde lo concreto. La actuación de las asambleas regionales frente a la Covid-19: la cooperación entre parlamentos en un tiempo de pandemia.

II. LA COOPERACIÓN INTERNACIONAL INTERPARLAMENTARIA. ESPECIAL ATENCIÓN A LA UNIÓN EUROPEA.

III. UNA APROXIMACIÓN COMPARADA: EL FEDERALISMO LEGISLATIVO EN ESTADOS UNIDOS Y CANADÁ. 1. Estados Unidos. 2. Canadá.

IV. LA COOPERACIÓN INTERPARLAMENTARIA, UNA ETAPA EN LA SENDA FEDERAL: EL FEDERALISMO LEGISLATIVO. BIBLIOGRAFÍA. 
La apertura de un nuevo espacio para la reflexión sobre el avance político, social y jurídico de un Estado es un motivo de alegría para todos. La Legebiltzarreko Aldizkaria - LEGAL - Revista del Parlamento Vasco y quienes han promovido su creación merecen también un aplauso, porque han materializado el sentir de que no todo está dicho, aun admitiendo que ha sido mucho, y que hay que seguir trabajando, escuchando, debatiendo, errando y acertando, en resumen, que hay que seguir viviendo y pugnando por un futuro mejor. El honor de tener un hueco en este número inaugural es un estímulo a contribuir con toda mi ilusión al éxito del proyecto y de su significado. Gracias.

Las primeras líneas que voy a plasmar son aquellas que siempre se sienten, pero que suelen quedarse en el tintero porque, en unos casos se dan por obvias, y en otros se entrevén en el grueso del texto y no aportan datos sustantivos, por lo que razonablemente se omiten. El contexto patológico, esperpéntico, terrible y real en el que se ha redactado esta reflexión no puede soslayarse. Escribir ha sido como agarrarse a la maroma del deber ser, de lo que tendría que ocuparnos y preocuparnos, pero que no es así. No es frivolidad, sino sensatez, lo que motiva a seguir con nuestras cuitas, sin perder la sensibilidad extrema con la que convivimos. Me viene a la memoria el prólogo de Federal Government, -publicado por vez primera en 1946- donde Kenneth Wheare se esforzaba por escribir sobre el federalismo en medio del dramático caos londinense de la Segunda Guerra Mundial, excusándose por no incorporar prolijas notas documentando su trabajo y procurando compensar esa carencia con profundas reflexiones sobre el significado del federalismo, que, al fin y a la postre, convertirían ese trabajo en uno de los referentes de esa propuesta organizativa que es la federación. Salvando las distancias en todos los sentidos, y con el recurso de internet, las notas de este trabajo no podrán ser todas las deseadas, pero materializan argumentos y contraargumentos, postulados y tributos que buscarán abrir nuevos espacios y vías alternativas a la contribución colectiva al pensamiento federal en y desde España.

La temática propuesta radica en ahondar en cómo la colaboración y cooperación interparlamentaria en un Estado descentralizado, en particular el Estado autonómico, ha contribuido a y puede sustentar la conformación de un substrato sólido y real de naturaleza federal. Algunas apreciaciones metodológicas pueden ser útiles para su comprensión. Se ha optado por implementar una metodología inductiva, en la que, a partir de análisis concretos, la reflexión se elevará a postulados más amplios y generales. En ese rastreo lege data de la colaboración y cooperación entre parlamentos regionales se abrirán varios frentes que se entrecruzarán: uno temporal, en el que se presentará una síntesis de lo que se ha hecho, se está haciendo y de lo que cabría realizar -retrospectiva, perspectiva actual y prospectiva-; otro comparado, que se centrará en los casos estadounidense y canadiense, sin perder el referente de cómo la cooperación interparlamentaria se ha asentado en un orden global, y otro material, abordando los distintos flancos de esa colaboración y cooperación, principalmente a nivel orgánico, procesal y normativo-axiológico -la colaboración interparlamentaria como principio 


\section{LA COLABORACIÓN \\ Y LA COOPERACIÓN INTERPARLAMENTARIA SUBESTATAL}

normativo-. Desde ese poso, se engarzará una propuesta final en la que se articulará una reflexión dialéctica sobre la concepción de la colaboración interparlamentaria territorial como garantía del pluralismo y como eslabón entre la unidad y la diversidad que sustenta la esencia de una federación.

La colaboración y la cooperación interparlamentaria son las coordenadas principales que marcan el desarrollo de las relaciones interparlamentarias, pudiendo entrever semánticamente un matiz de intensificación del vínculo de actuación o de trabajo conjunto, cuando hablamos de cooperar ("obrar juntamente con otro u otros para la consecución de un fin común", RAE), respecto a colaborar ("trabajar con otra u otras personas en la realización de una obra”, RAE). Estas categorías son diferenciables en teoría, especialmente si nos centramos en el terreno competencial ${ }^{1}$, pero se entrecruzan en la práctica, llevando a que el Tribunal Constitucional hable indistintamente de "colaboración y/o cooperación" (SSTC 31/2010, FJ 120 o 53/2017, FJ 16). El punto argumental del que partimos es el deber de colaboración que se encuentra "implícito en la propia esencia de la forma de organización territorial del Estado" y es consustancial "al modelo del Estado de las Autonomías", (tempranamente, SSTC 18/1982, FJ 14, 152/1988, FJ 6, y más reciente STC 78/2017, FJ 6, B, f), entre otras). Así, plantearemos una cooperación interparlamentaria de naturaleza orgánica, nacional e internacional, y una colaboración a nivel profesional, que, no obstante, pese a su naturaleza instrumental, puede ser más eficaz incluso que la anterior. En este afán introductorio de aislar semánticamente la cooperación interparlamentaria, entendida como "un ámbito más activo e intenso de relación que pueda servir para la mejora en el funcionamiento de dos o más instituciones parlamentarias, mediante el intercambio de experiencias, la reflexión conjunta o la puesta en común de medios personales y materiales" (Astarloa, 1998: 113), también hemos de proceder a su depuración respecto a otras prácticas, consecuencia de la cada vez mayor presencia de la política exterior en los parlamentos

1 En este sentido, la diferencia entre colaboración, cooperación y coordinación la podemos compendiar en que, a partir de un deber general de colaboración, la cooperación y la coordinación se conciben como parámetros de actuación en el ámbito del reparto competencial, preceptivos cuando lo establece el bloque de constitucionalidad y facultativos cuando no. Así, el principio de coordinación halla un anclaje constitucional (art. 149.1. 13, 15 y 16) con un contenido de carácter formal, conectado a un método de actuación, "la fijación de medidas y sistemas de relación que hagan posible la información recíproca, la homogeneidad técnica en determinados aspectos" (STC 140/2017, FJ 3 o tempranamente STC 32/1983, FJ 3). Por su parte, la cooperación apunta a una especie de ejercicio mancomunado o coejercicio de competencias, que incide en el ámbito de lo sustancial o material y que el Tribunal Constitucional ubicó en el difuso y metajurídico mundo de la voluntad o de los deseos: "la siempre necesaria voluntad de cooperación entre el Estado y” (STC 95/1986, FJ 5) las Comunidades Autónomas, a lo que agregaríamos de estas entre sí. (Tajadura, 2002: 75-83). 
(Elorriaga, 2001: 9) y de los legislativos y los parlamentarios en dicha política supraestatal, hasta el punto de poder hablar de una subespecie del Derecho parlamentario, como sería el parlamentarismo internacional (García Chourio, 2018: 12), que pivota en torno a la cooperación exterior de los órganos legislativos y de una "diplomacia parlamentaria" a la que se conectarían aquellas actividades de diálogo y contacto internacional entre miembros de los órganos legislativos, con un marcado carácter protocolario, propio de esta cultura de la diplomacia, que aunque a veces pueda solaparse, quedaría fuera de lo que vamos a analizar como propiamente cooperación interparlamentaria subestatal. Tampoco podemos ignorar una colaboración instintiva, espontánea, fruto de un mimetismo interparlamentario, que derivaría en una cooperación implícita o subliminal y cuya existencia ha contribuido a proveer de unas bases comunes de partida para cada impulso cooperativo. Así, nuestro objetivo se centrará en las sinergias cooperativas parlamentarias intraestatales, sobre las que se solapan las consecuencias de nuestro sistema de gobierno y legislación multinivel, y que son el primer estadio en la construcción de un modelo de federalismo legislativo.

\section{COOPERACIÓN ORGÁNICA INTERPARLAMENTARIA SUBESTATAL}

La implementación de los objetivos de la cooperación interparlamentaria a nivel subestatal en España se ha materializado con dos referentes básicos: COPREPA y CALRE. El avance en el intercambio de información y buenas prácticas entre los parlamentos autonómicos ha sido parejo a la creación y consolidación de ambas.

\subsection{COPREPA}

COPREPA $^{2}$ es un foro institucional de encuentro de los Presidentes de Parlamentos Autonómicos del Estado Español (art. 1 Reglamento COPREPA/http://www. coprepa2009.es/reglamento.html). Sus objetivos y funciones se centran en el intercambio de experiencias sobre el funcionamiento de las cámaras, el análisis de los problemas, retos y oportunidades a los que se enfrentan los sistemas parlamentarios, así como, en su caso, la aprobación de iniciativas tendentes a mejorar su funcionamiento o su intercomunicación. Su formalización se remonta al año 1997, donde, bajo la presidencia de las Cortes de Aragón, se miró al federalismo cooperativo germánico como un patrón a seguir. Particular referente fue la Conferencia de Presidentes de Parlamentos de los länder de la República Federal Alemana (Embid, 1987: 44-46). A partir de ahí, la temática que ha copado sus diálogos ha sido polarizada por los siguientes contenidos:

2 Datos obtenidos desde https://coprepa.es/. La última reunión del Plenario de la COPREPA, hasta la fecha, se desarrolló en Mérida, el 30 y 31 de enero de 2020, donde los presidentes y presidentas de cámaras legislativas territoriales asistentes rubricaron además una declaración institucional en la que se incidió en la necesidad de afrontar grandes retos que se plantean en la sociedad, como el fortalecimiento de la Unión Europea, la consolidación de las instituciones, el cambio climático, la igualdad de género y la lucha contra la despoblación. 
los reglamentos de las cámaras legislativas autonómicas y sus modificaciones; grupos parlamentarios y transfuguismo; el intercambio de información y la comunicación entre parlamentos; el estatuto de los parlamentarios; la relación legislativo-ejecutivo a nivel autonómico; la reforma institucional y los parlamentos autonómicos; la iniciativa municipal; la igualdad entre mujeres y hombres; la configuración del Senado como cámara de representación territorial; el ahorro energético; la construcción de la Unión Europea y el principio de subsidiariedad; la conexión con la ciudadanía y la transparencia parlamentaria; la necesidad de una voz única en la CALRE (Conferencia de Asambleas Legislativas Regionales de la Unión Europea) y el reto de la despoblación. El espejo de esta cooperación lo hallamos, indiscutiblemente, en la Conferencia de Presidentes de Parlamentos de la Unión Europea y del Parlamento Europeo (EU Speakers Conference), que desde 1999 reúne anualmente a los presidentes de los parlamentos nacionales de la Unión Europea y al presidente del Parlamento Europeo ${ }^{3}$.

Conforman la COPREPA los presidentes de los parlamentos regionales de las 17 asambleas legislativas de las comunidades autónomas españolas (Parlamento del País Vasco, Parlamento de Cataluña, Parlamento de Galicia, Parlamento de Andalucía, Junta General del Principado de Asturias, Parlamento de Cantabria, Parlamento de La Rioja, Asamblea Regional de Murcia, Cortes Valencianas, Cortes de Aragón, Cortes de Castilla-La Mancha, Parlamento de Canarias, Parlamento de Navarra, Parlamento de Extremadura, Parlamento de las Illes Balears, Asamblea de Madrid y Cortes de Castilla y León). El funcionamiento de la COPREPA se articula a través de los siguientes órganos: Plenario, Presidencia y Permanente. El Plenario es la asamblea integrada por los presidentes y las presidentas de los parlamentos autonómicos formalmente convocada a tal efecto. Se reúne, al menos, una vez al año, preferentemente en el mes de enero, y la duración de las sesiones es como mínimo de dos días. La Presidencia corresponde al presidente o presidenta de aquella Cámara a la que el Plenario encomiende la preparación y organización de la siguiente reunión -en el ejercicio 2020 recae en la presidenta de la Asamblea de Extremadura-. El mandato se inicia con la clausura del Plenario y termina con la clausura de la reunión sucesiva. La Presidencia se designa entre los candidatos que se hayan presentado, decidiéndose por consenso y, en su defecto, por mayoría absoluta. La Comisión Permanente o Permanente está integrada por quien

3 El Parlamento de la Presidencia saliente de la Unión Europea, (rotación establecida en la Decisión UE 2016/1316, del Consejo, de 26 de julio de 2016), en este momento el Parlamento de Finlandia, organiza en el primer semestre de cada año la reunión de dichos presidentes, a la que se han incorporado los presidentes de las asambleas de los países candidatos -la conferencia prevista para mayo de 2020 en Finlandia ha sido cancelada-. Las normas y procedimientos para la Conferencia de Presidentes de los Parlamentos de la UE se adoptaron en forma de directrices en la Conferencia que se celebró en Roma del 22 al 24 de septiembre de 2000 y, posteriormente, se revisaron en la Conferencia de Estocolmo del 14 al 15 de mayo de 2010 (The Stockholm Guidelines for the Conference of Speakers of EU Parliaments). Esta reunión viene precedida por la reunión de los secretarios de dichos parlamentos nacionales, Meeting of the Secretaries-General of the European Union Parliaments, que auanza los trabajos a abordar y desarrolla técnicamente sus contenidos. En el presente ejercicio, tres cuestiones eran los objetivos principales: activar y actualizar los mecanismos de cooperación interparlamentaria en la Unión Europea, el uso de la tecnología para potenciar dicha cooperación y la evaluación de Eurojust. 
ocupe la presidencia de la COPREPA y los presidentes titulares anteriores. No obstante, para preservar el pluralismo político y facilitar el consenso, se adopta el principio " 3 componentes +3 partidos" siempre que ello sea posible, conforme a las siguientes reglas complementarias:

a. Cuando los tres miembros de la Permanente pertenezcan al mismo partido político, podrán incorporarse a la misma hasta dos miembros más, siempre que pertenezcan a partidos distintos.

b. Cuando los miembros de la Permanente pertenezcan a dos partidos políticos, podrá incorporarse a la misma otro miembro, siempre que pertenezca a un partido político distinto de aquellos dos que ya cuentan con representación en la Permanente.

En los supuestos a) y b) serán los presidentes o las presidentas de los parlamentos autonómicos pertenecientes a partidos que no cuentan con presencia en la Permanente quienes deberán ponerse de acuerdo en la designación de aquel o de aquellas representantes que se incorporarán a la Permanente. Esa idea de consenso, con su doble acepción, de consenso positivo y consenso negativo -cuando alguno de los participantes no convenga con el acuerdo o declaración acordada, pero no oponga su veto- es el dato más relevante del proceso colaborador de este foro (art. 3 del Reglamento, que fue aprobado inicialmente el 11 de octubre de 2006).

En síntesis, el rol que desempeña la COPREPA se puede condensar en el siguiente: "la COPREPA debe servir como espacio de diálogo e intercambio de experiencias, para que el Parlamentarismo autonómico, el más cercano a los ciudadanos, continúe con su desarrollo, sea modelo de buenas prácticas y esté a la altura de lo que nuestra sociedad demanda a quienes han recibido el mandato de representarla", conforme a su declaración de León, de 26 de septiembre de $2014^{4}$.

\subsection{CALRE}

La CALRE (Conferencia de Asambleas Legislativas Regionales de la Unión Europea), fundada en 1997 en Oviedo (a partir de las diez tesis de Stuttgart, articuladas por el Centro Europeo de Investigación del Federalismo de Tubinga en colaboración con el legislativo del Land de Baden-Württemberg), es la conferencia de los presidentes de los parlamentos de los estados federados, autonomías o regiones con competencia legislativa de la Unión Europea ${ }^{5}$. En total aglutina a 74 regiones de ocho países que representan a más de 200 millones de habitantes. Específicamente, la CALRE integra los parlamentos de las comunidades autónomas españolas, los consejos regionales italianos, las asambleas de las regiones y comunidades belgas, los parlamentos de

4 https://coprepa.es/wp-content/uploads/2018/07/2014_Declaraci\%C3\%B3n-de-Le\%C3\%B3n.pdf

5 https://www.calrenet.eu/what-is-calre/organization-rules 
los länder alemanes y austríacos, el Parlamento autónomo de Åland (Finlandia), las asambleas regionales de las islas Azores y Madeira (Portugal) y las de Escocia, Gales e Irlanda del Norte (Reino Unido). Dos son los referentes que actúan como nexo entre estos integrantes: pertenecer a la Unión Europea y tener competencias legislativas. Estas características otorgan a la CALRE una forma de homogeneidad que es crucial para la determinación de objetivos comunes. Por su competencia legislativa, todas estas regiones tienen que integrar las normativas europeas a su propia regulación fase descendente- (Ordoñez Solís, 2000: 244), puesto que la integración en la Unión no ha modificado la distribución competencial interna (STC 208/1999. FJ 4). Sus objetivos se centran en contribuir a la participación democrática de las asambleas legislativas regionales dentro del marco de la Unión Europea mediante el fortalecimiento de las relaciones entre las asambleas regionales y, en particular, mediante el intercambio de buenas prácticas. A ello cabría agregar el respaldo a las actividades de cooperación transfronteriza de sus asociados y la coordinación de sus miembros en la participación en proyectos de desarrollo institucional organizados por terceras partes. Todo ello en el marco del pleno respeto al principio de autonomía de cada asamblea.

Identificar la naturaleza jurídica de la CALRE nos lleva a descartar su carácter de asociación, de conformidad con el ordenamiento jurídico español o de cualquiera de los Estados de la Unión Europea, si bien el Comité de las Regiones no duda en incluirla en las asociaciones europeas territoriales que representan a las autoridades locales y regionales con las que interactúa para implementar el diálogo estructurado ${ }^{6}$ (COM (2003) 811 FINAL), articulado sobre los principios de apertura, participación, coherencia y efectividad. Se trataría de un "foro interparlamentario multilateral" (Arce Janáriz, 2002: 5), un punto de encuentro de carácter político (un political network), de mero impulso jurídico, pero sin esa fortaleza y eficacia.

En lo que respecta a su organización y funcionamiento, la CALRE actúa a través de dos órganos: la Asamblea Plenaria, compuesta de los presidentes de todos los parlamentos que pertenecen a la conferencia, y la Comisión Permanente, con ocho presidentes de parlamentos regionales: uno por cada país al que corresponden las regiones representadas. La presidencia de la CALRE (que lo es tanto de la Comisión Permanente

6 V. gr. Dentro de la Comisión ECON del Comité Europeo de las Regiones (CDR), se ha articulado el denominado diálogo estructurado sobre los desafíos locales y regionales de los acuerdos comerciales de la UE. Es habitual la participación de la Asamblea de Regiones Europeas (AER), la Conferencia de Asambleas Legislativas Regionales Europeas (CALRE) y la Conferencia de Regiones Europeas con Poder Legislativo (REGLEG). Los diálogos estructurados tienen como objetivo garantizar que las asociaciones europeas que representan a las autoridades locales y regionales mantengan conversaciones periódicas con la Comisión Europea a los efectos de mejorar la legislación de la UE, garantizando que las opiniones de las asociaciones locales y regionales se tengan en cuenta antes de que comiencen los procesos formales de toma de decisiones, para garantizar una mejor comprensión de las directrices políticas de la UE y hacer que la UE sea más transparente y significativa para sus ciudadanos. El CDR por la presente actúa como intermediario, organizador y facilitador, debido a su fuerte uínculo con ambas partes. En 2016, el comité implementó un nuevo modelo que vincula cada diálogo con una de las comisiones del CDR y lo mantiene dentro de sus reuniones de comisión. (https://cor. europa.eu/es/news/Pages/CoR-to-become-observer-at-Advisory-Group-on-EU-trade-agreements.aspx) 
como de la Asamblea Plenaria) cambia cada año de país. En 2020 corresponde a la presidencia del Parlamento de Canarias, concretamente a Gustavo Matos Expósito.

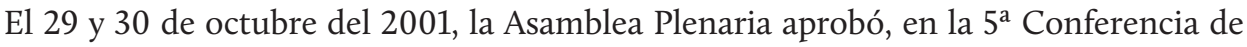
la CALRE, en Funchal (Madeira, Portugal), el vigente Reglamento de la CALRE, que regula la organización práctica y al que posteriormente se han introducido diversas modificaciones.

En sus diferentes conferencias se ha hecho un especial hincapié en la cooperación interparlamentaria (Declaración de Milán, 2004, $8^{\text {a }}$ Conferencia) y en una reivindicación del rol a desempeñar por los parlamentos regionales en la era de internet (Informe de los Presidentes de los Parlamentos del Valle de Aosta e Irlanda del Norte sobre los parlamentos regionales en la era de internet, Declaración de Madeira, 2001, $5^{\mathrm{a}}$ Conferencia) o con respecto a las nuevas tecnologías (Documento sobre los compromisos de los parlamentos regionales en relación con las nuevas tecnologías de la información, "Declaración de Reggio Calabria", 2003, 7ª conferencia). También se ha abierto un espacio a la cooperación reforzada entre parlamentos regionales, en función de las singularidades específicas de determinadas regiones, ya sean regiones insulares (la Declaración de los presidentes de las Asambleas legislativas de las Regiones Insulares Europeas miembros de la CALRE, Cagliari, el 2 de mayo de 2003: Declaración de Reggio Calabria, 2003, $7^{\mathrm{a}}$ conferencia), regiones del área euromediterránea (Declaración de Milán, 2004, 8ª Conferencia) o regiones capitales (Declaración final de la cuarta Conferencia de Presidentes de los parlamentos de las regiones capitales en la Unión Europea, celebrada en Berlín del 23 al 25 de febrero de 2003; la declaración se presentó como anexo a la "Declaración de Reggio Calabria", $2003,7^{\mathrm{a}}$ conferencia). Estos últimos parlamentos han desarrollado un foro específico integrado por los presidentes de las asambleas de las regiones capitales de la Unión Europea que gozan de potestad legislativa y en cuya región está ubicada la capital de su Estado respectivo: Parlamentos de Berlín, Bruselas, Lazio, Viena y Madrid. En lo que respecta a su dinámica de funcionamiento, los trabajos de este foro de presidentes de asambleas capitalinas tienen un paralelismo a la CALRE, concluyendo con una declaración final que es remitida a los respectivos gobiernos regionales, al Parlamento Europeo, a la Comisión Europea, al Comité de las Regiones de la UE, a la propia Presidencia de la CALRE y a los Gobiernos de los Estados de los que forman parte las regiones participantes (Alemania, Austria, Bélgica y España). La Asamblea de Madrid ha albergado su reunión constitutiva en 1999; la $5^{\text {a }}$ Conferencia de Presidentes de Parlamentos de Regiones Capitales de la Unión Europea, que tuvo lugar los días 26 y 27 de abril de 2006, en la que se abordaron cuestiones que afectan de manera especial a las regiones capitales: su financiación, las políticas de inmigración, la prevención de ataques terroristas y el diálogo entre las distintas culturas y religiones, y la $9^{\mathrm{a}}$, en el año 2010, que versaría sobre temas de vigente actualidad como la financiación de los servicios sociales en épocas de crisis y la financiación del transporte público en las 
regiones capitales. Esta conexión interorgánica también se produce entre COPREPA y CALRE, mediante la articulación de grupos de trabajo, por ejemplo, sobre "Igualdad y Reto Demográfico".

Es importante destacar que desde la CALRE se ha incubado otra iniciativa asociativa como es la Conferencia de Presidentes de Regiones con competencias legislativas de Europa (REGLEG), que toma como base esa regionalización con potestad legislativa, pero que conecta a los gobiernos regionales. Integra a 73 regiones de siete Estados miembros (Austria, Bélgica, Finlandia, Alemania, Italia, Portugal, España), una vez formalizada la salida del Reino Unido. En su funcionamiento hay una confluencia organizativa y temática con la CALRE, en el sentido de habilitar un puente de comunicación entre los gobiernos de la Unión y de ellos con las propias instituciones, sobre el principio base de la subsidiariedad.

Como dato positivo de esta cooperación, destaca que, en su esencia, especialmente en las relaciones interparlamentarias europeas, se ha buscado potenciar el "hecho parlamentario", apoyado o canalizado a través de un "hecho regional", es decir, es una cooperación más abierta y más democrática. En el lado oscuro, podemos apuntar que los temas abordados son dispares, invadiendo aspectos más propios de los ejecutivos, como la legitimación regional ante el Tribunal de Justicia (Arce Janáriz, 2005: 13), lo que acaba restando credibilidad a esta cooperación interparlamentaria. Así, el paralelismo CALRE-REGLEG tendría que tener mayores consecuencias y una mejor coordinación, lo que indudablemente repercutiría en una mayor eficacia. Hay que recordar que la conexión con el Parlamento Europeo de todas las organizaciones de carácter territorial se canaliza a través del Comité de Desarrollo Regional (REGI) y del Comité de Asuntos Jurídicos (REGI), en todo lo concerniente a la aplicación horizontal del principio de subsidiariedad, conforme a los Protocolos 1 y 2 del Tratado, en los que se configura a los parlamentos nacionales de los Estados miembros como los interlocutores primarios en el diálogo interparlamentario 7 . Sin embargo, la aspiración de la CALRE respecto a crear, dentro de la Comisión de Asuntos Constitucionales de la Eurocámara, una subcomisión de relación con los parlamentos regionales, que canalizaría las diferentes

7 El Tratado de Lisboa consolidó el importante papel de los parlamentos nacionales para garantizar el buen funcionamiento de la Unión, especialmente de la mano del principio de subsidiariedad, concentrando su participación tanto en una fase ascendente, como descendente de la legislación europea. El Parlamento Europeo ha revisado y modificado su Reglamento interno y ha establecido procedimientos administrativos para garantizar la aplicación adecuada de las nuevas disposiciones del Tratado. Además, en 2009 y 2014 , la Comisión de Asuntos Constitucionales del PE redactó varios informes de iniciativa que tratan específicamente sobre el desarrollo de las relaciones entre el Parlamento Europeo y los parlamentos nacionales. Estos informes condujeron a resoluciones no legislativas adoptadas por el plenario del PE que incluían una serie de propuestas para mejorar aún más las relaciones interparlamentarias. V. gr. Resolución del Parlamento Europeo, de 19 de abril de 2018, sobre la aplicación de las disposiciones del Tratado relativas a los parlamentos nacionales (informe Rangel); Resolución del Parlamento Europeo, de 18 de abril de 2018, sobre los informes anuales 2015-2016 sobre subsidiariedad y proporcionalidad (informe Delvaux); Resolución del Parlamento Europeo, de 16 de abril de 2014, sobre las relaciones entre el Parlamento Europeo y los parlamentos nacionales (informe Casini); Resolución del Parlamento Europeo, de 7 de mayo de 2009, sobre el desarrollo de las relaciones entre el Parlamento Europeo y los parlamentos nacionales en virtud del Tratado de Lisboa (informe Brok); Resolución del Parlamento Europeo, de 7 de febrero de 2002 , sobre las relaciones entre el Parlamento Europeo y los parlamentos nacionales en la integración europea (informe Napolitano) (https://www.europarl.europa.eu/ relnatparl/en/home/interparliamentary-cooperation.html). 
propuestas institucionales formuladas por dichas instituciones, no se ha formalizado. Con todo y como referencia más reciente, tras la constitución de un grupo operativo sobre subsidiariedad, proporcionalidad y "hacer menos pero de forma más eficiente", el 14 de noviembre de 2017 por el presidente de la Comisión, Jean-Claude Juncker y presidido por Frans Timmermans, en su informe de 10 de julio de 2018, son varias las propuestas que se formulan para potenciar el papel de los parlamentos regionales en el marco de las instituciones y órganos comunitarios ${ }^{8}$, pudiendo sintetizarse todas ellas en la necesidad de su futura recepción en los Tratados y en que desde la situación actual habría que promover que ese diálogo informal existente sea más estructurado para alcanzar una mayor eficacia (Recomendación n. ${ }^{\circ} 1$ ). Finalmente, que estemos ante foros políticos, no jurídicos, no es negativo per se, siempre y cuando ese impulso político sea sólido y ahonde en las necesidades reales de los ciudadanos, especialmente cuando lo que se busca es compensar el déficit democrático de nuestras instituciones, particularmente a nivel europeo. El reto está en la eficacia, en que todas estas prácticas cooperativas y colaborativas entre parlamentos potencien el hecho parlamentario, el papel y el liderazgo de los propios parlamentos. Donde tienen mucho terreno que abonar es en los aspectos procedimentales, de funcionamiento interno de las cámaras y de potenciación de la representatividad, que ha de ser integradora y correctora del monolitismo de los ejecutivos, aun cuando estos sean coaliciones o estén forzados a abandonar un patrón monocromo.

8 El informe responde a tres interrogantes que el presidente había planteado al grupo: cómo aplicar mejor los principios de subsidiariedad y proporcionalidad en las instituciones de la UE, cómo mejorar la participación de las administraciones locales y regionales en la elaboración y aplicación de las políticas de la UE, y si existen campos en los que puedan con el tiempo retransferirse competencias a los Estados miembros. El grupo operativo concluyó que en materia de subsidiariedad y proporcionalidad era necesaria una nueva forma de trabajar para que las autoridades locales y regionales y los parlamentos nacionales y regionales contribuyeran más eficazmente a la formulación de políticas de la UE y a la elaboración de nueva legislación. Según esta propuesta, todos los niveles de gobierno evaluarían con mayor coherencia la subsidiariedad y la proporcionalidad, para lo cual se basarían en un "modelo de red", una especie de lista de control sobre subsidiariedad y proporcionalidad. Un método común que debería ser usado por las instituciones y órganos comunitarios y por los parlamentos nacionales y regionales para abordar todas las cuestiones vinculadas a los principios de subsidiariedad, proporcionalidad y las bases procesales de la legislación nueva y de la existente. Se establece el carácter preceptivo de la consulta de los parlamentos nacionales a los parlamentos regionales en el contexto del control de subsidiariedad. Estos cambios formales en los roles y en la interacción entre los parlamentos nacional y regionales requerirían cambios en los Tratados y deberían ser considerados en el futuro. Con todo, dentro de lo preceptuado por las disposiciones de los Tratados vigentes, un diálogo más estructurado, aunque informal, podría asegurar que los parlamentos regionales con poder legislativo se impliquen de modo más efectivo en el proceso de control de la subsidiariedad (Recomendación n.․․ 1, p. 12). Al deber de los parlamentos nacionales de consultar a los parlamentos regionales cuando sus competencias se vean afectadas por la legislación comunitaria, se une el deber de la Comisión de recepcionar las opiniones razonadas y responder no solo a los parlamentos nacionales, sino también a los regionales, hecho que ha de reflejarse en su informe anual sobre subsidiariedad y proporcionalidad (Recomendación n.․2, p. 13). Otra curiosa recomendación de este grupo operativo para incrementar la capacidad de las instituciones regionales, de sus autoridades, y por ende de los parlamentos regionales, de participar en el proceso legislador europeo, es la de promover acciones innovadoras para comunicarse con los ciudadanos de la Unión Europea, por ello auala la articulación de un programa similar al ERASMUS, para políticos regionales y locales, entre ellos los parlamentarios regionales. (Recomendación n.․ 4, p. 15). La necesidad de mejorar la comunicación y la colaboración interorgánica se resalta para los parlamentos nacionales, los parlamentos regionales y el Comité de las Regiones, para lo que se recomienda un mejor y más eficaz uso de sus plataformas IT, a los efectos de compartir información. (Recomendación n.․ 7, p. 18). Report on the Task Force on Subsidiarity, Proportionality and "Doing Less More Efficiently" (https://ec.europa. eu/commission/files/report-task-force-subsidiarity-proportionality-and-doing-less-more-efficiently_es). 


\section{LA COLABORACIÓN PROFESIONAL}

Asumiendo ese tenue matiz entre colaboración y cooperación de las primeras líneas de este epígrafe, entendemos oportuno referir cómo los profesionales de los parlamentos territoriales en España han sido pioneros e impulsores de la idea de trabajo en conjunción como motor de una mejor praxis en sus respectivos quehaceres, a la par que como referente de la consolidación de una disciplina que es el Derecho parlamentario, en este caso autonómico.

\subsection{AELPA}

La Asociación Española de Letrados de Parlamentos (AELPA) es una asociación, constituida en 2004 por tiempo indefinido -al amparo de la Ley Orgánica 1/2002, de 22 de marzo reguladora del Derecho de asociación-, para crear y mantener vínculos estables entre sus miembros, teniendo como fines sociales la promoción de los intereses profesionales y culturales de los mismos (art. 3, Estatutos de la Asociación Española de Letrados de Parlamentos).

Son tareas de la asociación todas las que conduzcan al logro de los objetivos antes mencionados, como la organización de cursos, seminarios y conferencias, la edición de revistas y anuarios, etc. y, en general, cualesquiera otras de naturaleza análoga relacionadas con las funciones propias de sus miembros. En ese sentido, es una de las asociaciones más activas, siendo un referente de imprescindible consulta, no solo para sus asociados, sino para la academia, en materias como las bases de datos, generales -normativa parlamentaria, legislación y boletines oficiales- o en ámbitos materiales específicos, como el proceso catalán o la declaración de estado de alarma (https://aelpa.org/). Destacan sus publicaciones generales, como el Manual Aelpa del Parlamentario, Madrid, Aelpa-Wolter Kluwers, 2016 (Coord. Sarmiento Méndez) o las temáticas, fruto de las diferentes jornadas avaladas por la asociación (https://aelpa.org/ enlaces-de-bibliografia-y-bases-de-datos/).

Son miembros de pleno derecho de la asociación los letrados unidos a cualquiera de los parlamentos, asambleas legislativas o cortes existentes en el Estado español, por una relación de servicio profesional de carácter estatutario y, como tal, integrados en los respectivos cuerpos o plazas de tal nombre, que soliciten su ingreso a la junta directiva. Su estructura y funcionamiento se asemejan al de cualquier asociación (junta directiva, con un presidente, vicepresidente, secretario y tesorero).

\subsection{ASEINPA}

Es la Asociación Española de Interventores de Parlamentos, que aglutina a los profesionales encargados de la vigilancia de la legalidad en la gestión económica de las instituciones parlamentarias. Entre sus preocupaciones, tal y como evidencia la programación de las jornadas de dicha asociación, está el control de las subvenciones parlamentarias o la auditoría de las cuentas anuales de los parlamentos desde un punto 
de vista comparado entre los parlamentos de España, pero sobre todo la necesidad de ejercer ese trabajo de forma reglada, con autonomía y plena independencia frente a los órganos a controlar, a los efectos de lograr la transparencia de la gestión económica.

\section{REDES DE COOPERACIÓN INTERPARLAMENTARIA}

Alcanzar los objetivos trazados por la cooperación interparlamentaria requiere un impulso orgánico, pero a la vez una estructura que lo sustente y apoye. Esta se ha conseguido mediante la creación de una plataforma para el intercambio de información y documentación entre los parlamentos autonómicos y por la apertura de la vida y la actividad parlamentaria a través de las redes sociales.

\subsection{Red_Parlamenta}

Bajos los auspicios de la COPREPA, e implementando sus objetivos, se crea la Red_ Parlamenta, cuya formalización se remonta al acuerdo adoptado en Mérida, en mayo de 2010, con la finalidad de crear una plataforma para el intercambio de la información parlamentaria, definido en su convenio de creación como un mecanismo estable de colaboración mutua en el ámbito de la documentación e información, "será un sistema integral para el intercambio de información entre las Asambleas integrantes del Convenio, sustentado en los principios de colaboración, comunicación y mutua confianza" (cláusula primera del convenio) ${ }^{9}$.

La titularidad de dicha plataforma corresponde a todos los titulares que forman parte de la red, que son quienes asumen de forma solidaria y compartida la responsabilidad relativa tanto a la gestión como a los costes derivados del desarrollo y mantenimiento del portal (cláusula tercera del convenio). Los contenidos disponibles, desde noviembre de 2014 para todo el público, se estructuran en los siguientes bloques: actividad parlamentaria (publicaciones oficiales — boletines; diarios de sesiones- buscadores de tramitación parlamentaria; iniciativas legislativas; reglamentos y resoluciones; tramitaciones de las reformas de los Estatutos de Autonomía; emisiones y videotecas de las sesiones parlamentarias de los distintos parlamentos); recursos y colecciones (bases bibliográficas de los parlamentos; revistas, que nos indican en qué biblioteca se puede encontrar la revista con un enlace al texto completo si se halla volcado en internet; guías de recursos -sobre distintos temas, como elecciones, parlamentos o el Brexit, elaborados por dos parlamentos como son el catalán y las Corts Valencianes-; jurisprudencia compilada por el Parlamento de Andalucía en materia parlamentaria y en materia electoral por las Cortes de Aragón; otros recursos -históricos elaborados por el Parlamento de Cantabria y por la Junta General del Principado 
de Asturias- y web social, donde se aloja un directorio de redes sociales de los departamentos de información y documentación de los distintos parlamentos); actividad documental (dosieres de documentación y bibliografías temáticas; boletines de sumarios y boletines de actualidad y e-comisiones -información, documentación, actividad parlamentaria y legislación básica de interés para los miembros de las Comisiones-) y finalmente un enlace sobre información electoral en el que se recopilan los datos más relevantes sobre las elecciones autonómicas, desde doctrina jurisprudencial hasta sondeos, candidaturas y resultados. Hay que mencionar que en la gestación de esa red tuvo un interesante papel la Federación Española de Sociedades de Archivística, Biblioteconomía, Documentación y Museística (FESABID), y que su buen hacer tuvo un temprano reconocimiento, al obtener el VII Premio Nacional de la Sociedad Española de Documentación e Información Científica (SEDIC).

Este formato de cooperación interparlamentaria se refleja también en el ámbito europeo, con otros escenarios como la plataforma IPEX (Interparliamentary EU Information Exchange) que facilita el intercambio de documentos de interés para la Unión entre los parlamentos de la UE, o en el Centro Europeo de Investigación y Documentación Parlamentaria (CEIDP), que canaliza las peticiones de información cuando un determinado parlamento desea informarse de forma más detallada sobre las prácticas y las políticas de otros países de la UE.

\subsection{Los parlamentos autonómicos en redes sociales}

Desde la propia Red_Parlamenta se promueve la compilación de la actividad de los parlamentos autonómicos en redes sociales, a la par que se impulsa su propia presencia (red_parlamenta @red_parlamenta). El punto de partida de los parlamentos autonómicos se focalizó en la relación con la sociedad a través de los medios de comunicación tradicionales, prensa, radio y televisión. En la década de los noventa las asambleas inauguraron sus páginas webs y ya en la primera década del siglo XXI llegaron primero los blogs y luego las redes sociales, a través de las que se ha buscado "añadir una prolongación virtual a la acción política real" (Greciet, 2018: 3574).

La principal razón para introducirse en redes sociales puede sintetizarse en un objetivo: estar allí donde están los ciudadanos y trasladar su presencia e información en las fuentes que consultan, siendo lo más inclusiva posible (Mergel, 2013: 330). Los medios sociales de comunicación pueden usarse con distintos fines: la información (provisión de material, información de antecedentes, alianzas entre medios e información general para el público), la educación (difusión de actividades, material pedagógico y otros recursos para estudiantes y docentes), la divulgación (vínculos y asociaciones con la sociedad civil, con el sector empresarial y con otros grupos, facilitando el acceso del público al parlamento) y la interacción (habilitar canales activos para informar a los ciudadanos y relacionarse con ellos, para pedir propuestas y despertar el interés por las actividades parlamentarias) (Williamson, 2013: 11). 
Las redes sociales que han utilizado los parlamentos autonómicos son mayoritariamente Twitter, Facebook, Linkedin, Youtube e Instagram. En menor medida, Flickr, Google + y Pinterest. El primer parlamento en incluir su presencia en redes sociales fue el canario, en 2008. Le seguirían en 2009 Cataluña, Galicia, Navarra y Extremadura (Rodríguez-Andrés y Álvarez Sabalegui, 2018: 996).

Con todo, el balance de esta interacción social en redes de los parlamentos no parece haber desplegado todo su potencial, ni alcanzado sus objetivos. Ese ideal acercamiento de los ciudadanos a los parlamentos no se ha logrado (Campos-Domínguez, 2014: 45), porque se siguen concibiendo las redes sociales como un tablón de anuncios, obviando la dimensión de feedback que incorporan y que las singularizan. Así, las redes sociales, a pesar de tener un potencial discursivo e interactivo muy importante, quedan comprimidas a una función de presencia y de divulgación informativa de la actividad parlamentaria, más bien testimonial, asociada a un disciplinado deseo de cumplir con el expediente de modernización, cercanía y transparencia, pero lejos de una función deliberativa y mucho menos participativa (Giraldo-Luque, 2017: 1294). "La mayoría de los perfiles siguen siendo usados de forma prioritaria como plataformas de difusión unidireccional de información” (Rodríguez-Andrés y Álvarez Sabalegui, 2018: 1002).

\section{PARLAMENTOS DIGITALIZADOS, ABIERTOS, CONECTADOS A LA SOCIEDAD Y COLABORATIVOS}

Reflexionar sobre la colaboración y cooperación interparlamentaria requiere insertar una exigua referencia a cómo esta dimensión colaborativa de los parlamentos ha transitado sobre uno de sus principales retos actuales, que es la conversión de nuestros parlamentos en parlamentos abiertos (García-Escudero, 2015: 206). Esta concepción deriva de la aplicación a la institución parlamentaria de la doctrina del gobierno abierto y supone la creación de una serie de derechos, pero entendemos que también de una serie de obligaciones por parte de los ciudadanos para que su implementación sea plena. Si se habilitan cauces para participar en las tareas parlamentarias, los ciudadanos hemos de usarlos, además, de una forma constructiva y responsable. Este concepto de parlamento abierto está en proceso de construcción y consolidación, e incorpora una dimensión cambiante que implica su constante reformulación y evolución, todo ello sobre una base constitucional que se sintetiza en la voluntad de "establecer una sociedad democrática avanzada", tal y como se refleja en el preámbulo, pero que se afianza en el conjunto del articulado (arts. 9.2 y 3, 23, 29, 48,77 y 105 , entre otros).

Los parlamentos autonómicos han sido alumnos aventajados en esa carrera hacia la apertura de sus actuaciones, a veces de un modo febril (Cabo, 2013: 62), pudiéndose destacar la labor de alguno de ellos, como el vasco (con herramientas 
como Zabalik, Parte hartu o ADI -Aporta, Debate, Influye-), el catalán, el canario o el cántabro (Rubio, 2018: 13-14). Sin embargo, lo que ahora más nos importa es cómo la conversión de nuestros parlamentos en instituciones abiertas y digitalizadas ha propiciado una vis colaborativa entre ellos. Pese a que la doctrina ha reparado en que resulta difícil destacar herramientas específicamente colaborativas en los parlamentos españoles, referenciando como ejemplo la Oficina Presupuestaria de las Cortes Generales (Aranda, 2017: 31), podemos destacar algunas experiencias más amplias que implican una colaboración, tanto a nivel interparlamentario, como en lo que se refiere a la utilización de las TIC para potenciar la participación conjunta e interconectada entre diferentes segmentos y grupos de interés a través de cauces parlamentarios. En ese sentido, la Alianza para el Gobierno Abierto (Open Government Partnership, OGP), integra un Legislative Openness Working Group ${ }^{10}$, liderado por la Comisión de Transparencia del Parlamento de Chile, en colaboración con el National Democratic Institute (NDI) ${ }^{11}$, que incorpora entre sus objetivos el intercambio de experiencias en materia de parlamentos abiertos. El NDI es una organización no gubernamental que promueve prácticas e instituciones democráticas en todo el mundo. Fundada en 1983, destaca por haber sido pionera en la defensa del uso de la tecnología como un componente integral del desarrollo democrático. Es cofundadora de OpeningParliament.org, red en la que participan más de 180 organizaciones de 80 países, que monitoriza la actividad parlamentaria y persigue un mayor aperturismo del proceso legislativo. Bajo sus auspicios se ha elaborado la Declaración de Transparencia Parlamentaria, que es un conjunto de principios de actuación general adoptados por más de 70 organizaciones de la sociedad civil mundial y que postula una serie de buenas prácticas para alcanzar y progresar en el ideal de un parlamento abierto. La defensa del intercambio de buenas prácticas entre los diferentes parlamentos es uno de los pilares de esta guía ${ }^{12}$.

\section{LA COOPERACIÓN INTERPARLAMENTARIA SUBESTATAL COMO PRINCIPIO ORGANIZATIVO EN LA TEORÍA CONSTITUCIONAL}

La doctrina iuspublicista no ha construido una teoría jurídica sobre las funciones de cooperación parlamentaria, ni a nivel interno (Astarloa, 1998: 115), ni a nivel europeo (Fernández Alles, 2010: 77), por ello es interesante recabar no solo cómo se han implementado, sino cómo se provee una cobertura normativa a dicha praxis. En ese sentido, sobre la base del establecimiento de una sociedad demo-

10 https://www.opengoupartnership.org/stories/legislative-openness-comes-to-ogp/ 
crática avanzada, la clave la hallamos en la conciliación de los atributos de soberanía y autonomía parlamentaria con dicha cooperación, impulsada por un modelo territorial descentralizado y multinivel. El referente es el concepto de Estado constitucional cooperativo/ Der kooperative Verfassungsstaat ${ }^{13}$ (Häberle, 2018: 2), y dentro de él, cobrará un pleno sentido el referente al federalismo cooperativo, en una conexión género-especie. El constitucionalismo se conecta al valor de la cooperación, al igual que resulta inherente al mismo, la paz, la justicia, los derechos fundamentales, el interés general, la seguridad o las estructuras del Estado de derecho, incluidas las territoriales. Eso supone concebir que el constitucionalismo es el pilar del ordenamiento jurídico y social y que en esa conexión la Constitución tiene que incorporar la pluralidad. Así, la Constitución de 1978 inserta esa acepción de Estado constitucional cooperativo (arts. 1, 2, 9.2 o títulos Ill y VIII; de modo expreso la apelación a la cooperación funcional de las comunidades autónomas y el Estado puede referenciarse en los arts. 69.5 -Senado-, 87.2 -iniciativa legislativa-, 131.2 -planificación de la economía-, 145.2 -acuerdos y convenios de cooperación-, 166 -reforma de la Constitución-). La democracia ciudadana, propia de un Estado de derecho, se manifiesta a través de las múltiples conexiones cooperativas que se producen en el Estado constitucional, siendo los parlamentos, en particular los parlamentos autonómicos, unas instituciones, unos actores privilegiados de ese patrón cooperativo y colaborativo. El fortalecimiento normativo de ese cariz cooperativo de nuestro Estado lo hallamos en la legislación estatal (v. gr. principios de las relaciones interadministrativas, art. 140 de la Ley 40/2015, de 1 de octubre, de Régimen Jurídico del Sector Público), y en la legislación autonómica, particularmente en sus Estatutos. Especialmente importante en ese impulso colaborativo fueron las diversas reformas estatutarias que han regulado esa cooperación (Montilla, 2011: 164-175) y (Ruiz Robledo, 2008: 485), especialmente en lo que se refiere a acción exterior. Con todo, lo más interesante a los efectos del presente discurso es cómo los reglamentos de las cámaras se han aproximado a la misma, integrándola como un principio de las relaciones interparlamentarias. Así, el Reglamento de las Cortes de Aragón (aprobado en Sesión Plenaria celebrada el día 28 de junio de 2017), cuyo artículo 8 establece: “Las Cortes de Aragón, en su condición de máxima representación del pueblo aragonés, fomentarán las relaciones de solidaridad, colaboración y cooperación con las Cortes Generales y con los demás Parlamentos autonómicos". En consecuencia, la colaboración interparlamentaria abandona paulatinamente el terreno lege ferenda, para consolidarse en el lege data, teniendo

13 P. Häberle, "Die offene Gesellschaft der Verfassungsinterpreten" (1975) y "Verfassungsinterpretation als öffentlicher Prozeß -ein Pluralismuskonzept" (1978), trabajos presentes en la recopilación del mismo autor, Die Verfassung des Pluralismus, Athenäum, Königstein/Ts., 1980, pp. 306-7. En castellano, Xabier Arzoz, “La sociedad abierta de los intérpretes constitucionales. Una contribución para la interpretación pluralista y procesal de la Constitución”, en la recopilación de P. Häberle (1996) 
como eslabón una práctica cada vez más consolidada y fecunda, y un reto, que es el de contribuir al enraizamiento del federalismo, un federalismo necesariamente cooperativo.

\section{A MODO DE ILUSTRACIÓN, DESDE LO CONCRETO. LA ACTUACIÓN DE LAS ASAMBLEAS REGIONALES FRENTE A LA COVID-19: LA COOPERACIÓN ENTRE PARLAMENTOS EN UN TIEMPO DE PANDEMIA}

El coronavirus es un top concern, también en un contexto de la cooperación interparlamentaria. A través de sus distintas materializaciones se han habilitado recursos para afrontar este nuevo contexto. Entre todos los foros de canalización de la cooperación interparlamentaria ha sido la National Conference of State Legislatures la más activa (https://www.ncsl.org/research/health/ncsl-coronavirus-covid19-resources.aspx). lanzando un rico panel de recursos, estructurados por materias y emitido en forma de blogs, podcasts o webinars (v. gr., especialmente interesante fue COVID-19 and Elections), pensando expresamente en los legisladores estatales. Más tímida ha sido la respuesta de la CALRE, donde nos encontramos con una comunicación de su presidente, Matos Expósito, en la que se envía un mensaje de apoyo y solidaridad desde el que se apela a una Europa unida, más fuerte y más igualitaria (https://www.calrenet. eu/archives/9906), sin que se paute estrategia o práctica alguna a seguir de modo conjunto por sus parlamentos miembros ${ }^{14}$.

Los parlamentos autonómicos no han partido de un guion comunicado. Formalmente, la retina se ha hecho eco de ponentes que hablan en soledad, y materialmente, las comparecencias de los presidentes autonómicos, la constitución de comisiones parlamentarias sobre la COVID-19, las reuniones telemáticas de las diputaciones permanentes allí donde se había disuelto el parlamento, (País Vasco y Galicia) con declaraciones institucionales de relevancia que afectan a la suspensión de elecciones, al debate de proposiciones no de ley vinculadas a la COVID-19, declaraciones institucionales o la ausencia de la COVID-19, más allá de la noticia sobre el teletrabajo de su personal. Aquí cabría coordinar, con más urgencia y eficacia que nunca. El reto está trazado. Que esta pandemia y las extremas circunstancias en las que nos hallamos sirvan para reconciliarnos con el compromiso de contribuir a mejorar la vida de los ciudadanos, desde un compromiso de colaboración y cooperación leal, en este caso entre parlamentos autonómicos.

14 En ese mismo sentido, más testimonial que eficaz, nos encontramos los pronunciamientos de otras organizaciones de cooperación interparlamentaria, desde la UIP, https://www.ipu.org/parliaments-in-time-pandemic; Parlamento centroamericano https://parlacen.int/inicio ECOWAS https://www.ecowas.int/covid-19/ o PARLATINO https://parlatino.org/news 


\section{LA COOPERACIÓN INTERNACIONAL INTERPARLAMENTARIA. ESPECIAL ATENCIÓN A LA UNIÓN EUROPEA}

Como complemento a este glosario de referentes de cómo se aborda orgánicamente la cooperación interparlamentaria, hemos de hacer una escueta referencia a la UIP, Unión Interparlamentaria, decana de esa colaboración. Fundada en 1889 y con sede en Ginebra, su diferencia de otras organizaciones internacionales es que no es una organización intergubernamental sino una institución para el fomento de la cooperación de los parlamentos entre sí, con el sistema de Naciones Unidas y de la paz y la democracia a través del diálogo político. Cuenta con 178 parlamentos nacionales afiliados y 12 agrupaciones parlamentarias territoriales asociadas, y goza del estatus de observador permanente dentro del sistema de Naciones Unidas (https://www.ipu.org/about-ipu/members).

El mandato de la UIP se concentra en cinco áreas específicas, la mayoría de cuyos proyectos están dirigidos a parlamentos de países en vías de desarrollo: el establecimiento de normas y directrices para los parlamentos; la formación y capacitación de los parlamentarios; la promoción y protección de los derechos humanos; la igualdad de género en política; elaboración de la agenda del desarrollo y del buen gobierno. La Unión Interparlamentaria colabora con instituciones del sistema de Naciones Unidas (PNUD, UNITAR, Alto Comisionado para Derechos Humanos, etc.) y organiza seminarios y talleres dentro de sus áreas de interés con objeto de que los parlamentos nacionales asuman una mayor responsabilidad e implicación en las relaciones internacionales a través de una serie de medidas nacionales, regionales y globales.

Otros referentes internacionales de la cooperación interparlamentaria, sin agotar la casuística, y con la intención de ratificar la idea de la cooperación interparlamentaria, entremezclada con el Derecho internacional y el institucionalismo interestatal, con presencia de parlamentos estatales y parlamentos territoriales de estados federados, es un signo de una nueva concepción global del parlamentarismo, serían: Parlamento Andino (la Comunidad Andina (CAN) está compuesta por: Bolivia, Colombia, Ecuador y Perú. https://parlamentoandino.org/); Parlamento Centroamericano (PARLACEN) (compuesto por parlamentarios de Guatemala, Honduras, El Salvador, Nicaragua, República Dominicana y Panamá. Como observadores permanentes se han acreditado el Senado del Estado Libre Asociado de Puerto Rico y la delegación de observadores permanentes de la Cámara de Diputados de los Estados Unidos Mexicanos. http://www.parlacen.int/Inicio.aspx; East African Legislative Assembly (EALA) (compuesta por parlamentarios de Burundi, Kenia, Ruanda, Sudán del Sur, Tanzania y Uganda. http://www.eala.org/); Asamblea Interparlamentaria de Naciones Miembros de la Comunidad de Estados Independientes/ Interparliamentary Assembly of Member Nations of the Commonwealth of Independent States (CIS) (aglutina los parlamentos de la Federación Rusa, Azerbaiyán, Armenia, Bielorrusia, República de Moldavia, Kazajistán, Kirguistán, Tayikistán, Uzbekistán y Ucra- 
nia. Como observador, la República Islámica de Afganistán. https://iacis.ru/eng/); Inter-Parliamentary Committee of the West African Economic and Monetary Union (WAEMU) (Benín, Burkina Faso, Costa de Marfil, Guinea Bissau, Mali, Níger, Senegal y Togo. http://www.uemoa.int/); Parlamento Latino Americano y Caribeño (PARLATINO) (Sus miembros son los parlamentos de los Estados de América central, el Caribe y América del Sur. http://www.parlatino.org/); Parliament of the Central African Economic and Monetary Community (CEMAC) (formado por Camerún, África Central, Congo, Gabón y Chad. http://www.cemac.int/); Parliament of the Economic Community of West African States (ECOWAS) (el Parlamento está compuesto por 115 escaños. Cada uno de los 15 Estados miembros tiene un mínimo garantizado de cinco escaños. Los escaños restantes se comparten sobre la base de la población. En consecuencia, Nigeria tiene 35 escaños; Ghana, ocho escaños; Costa de Marfil, siete escaños, mientras que Burkina Faso, Guinea, Malí, Níger y Senegal tienen seis escaños cada uno. Los otros, Benín, Cabo Verde, Gambia, Guinea Bissau, Liberia, Sierra Leona y Togo tienen cinco escaños cada uno. http://parl.ecowas.int/); Asamblea Parlamentaria de la Francofonía (APF) (Entre sus miembros destacan Francia, Canadá, Rumanía, Camboya, Madagascar o la República Democrática del Congo, pero también parlamentos subnacionales como el de Quebec, Ontario o Manitoba. Entre sus asociados nos encontramos, igualmente, parlamentos subnacionales como los de las provincias canadienses de la Columbia Británica, Saskatchewan o Alberta, o Estados como Polonia o Lituania. Entre los observadores, podemos referir a Méjico, pero también a los parlamentos de estados federados como Louisiana, New Hampshire y Maine. http://apf.francophonie.org/). Este último referente, el de la Asamblea Parlamentaria de la Francofonía, es especialmente interesante ante nuestros ojos, porque, como veremos seguidamente, será uno de los pilares que nos faculte a sustentar un federalismo legislativo embrionario en el caso canadiense, por la mencionada participación de los legislativos de algunas de sus provincias.

La Unión Europea ha convertido la cooperación interparlamentaria en un sello identitario, a través del cual también ha buscado su consolidación. Los principales objetivos de la cooperación parlamentaria de la Unión son: promover el intercambio de información y buenas prácticas entre los parlamentos nacionales y el Parlamento Europeo, con miras a reforzar el control parlamentario, la influencia y la potestad parlamentaria de investigación; asegurar el ejercicio efectivo de las competencias parlamentarias, en particular en la monitorización de los principios de subsidiariedad y proporcionalidad, y promover la cooperación con los parlamentos de terceros países. El marco normativo ${ }^{15}$ que avala dicha cooperación interparlamentaria remite al Tratado de Lisboa, (art. 12: "Los Parlamentos nacionales contribuirán activamente al buen 
funcionamiento de la Unión"; protocolos n. ${ }^{\circ} 1$, El cometido de los Parlamentos Nacionales en la Unión Europea y n. ${ }^{\circ}$ 2, Protocolo sobre la aplicación de los principios de subsidiariedad y proporcionalidad), la legislación secundaria de la Unión y por los acuerdos entre el Parlamento Europeo y los parlamentos nacionales. Los instrumentos para su canalización, que hemos ido insertando en el discurso previo, se compendian en los siguientes: la Conferencia de Presidentes de Parlamentos de la Unión Europea (The EU Speakers' Conference, EUSC) ${ }^{16}$; COSAC (Conferencia de Órganos Especializados en Asuntos Comunitarios $)^{17}$; La Conferencia Interparlamentaria para la Política Exterior, de Seguridad Común y la Política Común de Seguridad y Defensa (IPC CFSP/CSDP) ${ }^{18}$; La Conferencia Interparlamentaria sobre la Estabilidad, la Coordinación Económica y la Gobernanza en la Unión Europea (IPC SECG) ${ }^{19}$; Grupo interparlamentario de investigación sobre Europol ${ }^{20}$, sobre Eurojust ${ }^{21}$ o sobre la Agencia Europea de Fronteras y Guardacostas ${ }^{22}$. A todas estas conferencias se han de agregar otros recursos para la cooperación interparlamentaria de carácter puntual, organizados por el parlamento del Estado miembro que ocupa la presidencia rotativa del Consejo de la UE y el Parlamento Europeo. Estas pueden tener lugar en varios formatos, como reuniones parlamentarias conjuntas, reuniones de comités conjuntos o reuniones de la Comisión Interparlamentaria (ICM) organizadas por el Parlamento Europeo. El reto radica en evitar la superposición y la duplicación de dichas actividades con las reuniones interparlamentarias permanentes.

16 Es un foro para el intercambio de opiniones, información y experiencias entre los presidentes de los parlamentos nacionales y el presidente de la Unión Europea. Vid. supra nota 2.

17 Los miembros de los comités de los parlamentos nacionales que se encargan de los asuntos de la UE y los miembros del Parlamento Europeo se reúnen dos veces al año durante una conferencia de órganos especializados en asuntos comunitarios, más conocida habitualmente por el acrónimo francés COSAC, para intercambiar información y buenas prácticas, y para debatir cuestiones de interés común para Europa. Regulada por el artículo 10 del Protocolo sobre el rol de los Parlamentos Nacionales en la Unión Europea, tiene la función de canalizar la información recibida tanto al Parlamento Europeo, como al Consejo o la Comisión. Rules of Procedure of the Conference of Parliamentary Committees for Union Affairs of Parliaments of the European Union (2011/C 229/01) (http://ipex.eu/IPEXL-WEB/dossier/files/ download/082dbcc564afa0210164b2e954b4030b.do).

18 Esta Conferencia establece un marco para el debate y el intercambio de información y buenas prácticas en el Área de Política Exterior y de Seguridad Común para garantizar que tanto los parlamentos nacionales como el Parlamento Europeo dispongan de la máxima información para acometer sus obligaciones en este ámbito. Rules of Procedure of the Inter-Parliamentary Conference for the Common Foreign and Security Policy and the Common Security and Defence Policy (https://secure.ipex.eu/IPEXL-WEB/dossier/files/download/082dbcc54b222e18014b504 0e5453653.do).

19 Esta Conferencia establece un marco para el debate y el intercambio de información y buenas prácticas para la aplicación del Tratado de Estabilidad, Coordinación y Gobernanza en la Unión Económica y Monetaria. Rules of Procedure of the Interparliamentary Conference on Stability, Economic Coordination and Governance in the European Union.

20 Este grupo monitoriza las actividades de la Europol buscando su transparencia y control. Se fundamenta en el artículo 88 del Tratado y en el artículo 51 de la Europol, y se explicita en las Rules of Procedure of the Joint Parliamentary Scrutiny Group on Europol.

21 Reglamento (UE) 2018/1727 del Parlamento Europeo y del Consejo, de 14 de noviembre de 2018, sobre la Agencia de la Unión Europea para la Cooperación Judicial Penal (Eurojust) y por la que se sustituye y deroga la Decisión 2002/187/JAI del Consejo PE/37/2018/REV/1.

22 Reglamento (UE) 2019/1896 del Parlamento Europeo y del Consejo, de 13 de noviembre de 2019, sobre la Guardia Europea de Fronteras y Costas y por el que se derogan los Reglamentos (UE) n. $1052 / 2013$ y (UE) 2016/1624. 
Esta intensa actividad de cooperación interparlamentaria no podría desarrollarse sin unas infraestructuras de apoyo, como el Encuentro de los secretarios generales de los parlamentos europeos (art. 8 de la Guía de Estocolmo para la Conferencia de Presidentes de los Parlamentos de la UE, vid. supra nota 2) o las oficinas de los distintos parlamentos nacionales en Bruselas (Neuhold, 2016: 242), pero sobre todo a partir de bases de datos como IPEX (InterParliamentary EU information eXchange), una plataforma accesible al público para el intercambio de información entre los parlamentos nacionales y el Parlamento Europeo, en el que se incluye un calendario de dichos encuentros interparlamentarios y de los trabajos desarrollados por el Centro Europeo de Investigación y Documentación Parlamentaria (ECPRD o CEIPD), compartida por el sustento del Parlamento Europeo y el Consejo de Europa (https://ecprd.secure.europarl.europa. eu/). Con todo ello vemos el mismo esquema explicitado para la cooperación interparlamentaria subestatal, pero a nivel europeo.

Una valoración de todas estas experiencias colaborativas es su carácter instrumental, centrada en la comunicación de problemáticas comunes. A nivel global podemos referenciarlas como un apoyo a la consolidación de la democracia parlamentaria, a partir de infraestructuras que trascienden a cada Estado. A nivel europeo, su reto es ahondar la participación y la conexión entre ciudadanos e instituciones, contribuyendo a paliar ese déficit democrático que se achaca de modo tan recurrente a las instituciones comunitarias. Sobre esa base, su principal aportación es técnica: habilitar herramientas para consolidar y facilitar los trabajos legislativos. En el ámbito del deber ser/sollen, su reto principal radica en plantear aquellas cuestiones que trascienden a los propios Estados y a sus territorios, buscando respuestas globales parlamentarias allí donde los acuerdos intergubernamentales no pueden o no quieren llegar. El actual contexto de pandemia global es el más idóneo para tal praxis.

\section{UNA APROXIMACIÓN COMPARADA: EL FEDERALISMO LEGISLATIVO EN ESTADOS UNIDOS Y CANADÁ}

El término federalismo legislativo es el eslabón que nos facultará a hacer un tenue guiño al ámbito comparado, a la vez que a avanzar en lo que será la tesis principal de este trabajo: la contribución de la colaboración de los legislativos territoriales a crear y consolidar una estructura y unas relaciones federales en un Estado. Por federalismo legislativo entendemos un proceso colaborativo entre instituciones de los estados federados en el que las asambleas legislativas desarrollarían un papel activo, apostando por un posicionamiento respecto a cuestiones federales, por una minoración de la disciplina de partido y por un refuerzo del papel de los propios parlamentos, junto a una dimensión activa en la monitorización de las tareas legislativas de los propios 
parlamentos estatales. Los supuestos a comentar son Estados Unidos y Canadá23. No obstante, este referente a la casuística comparada no quiere soslayar una referencia al caso germano, que sirvió como inspiración para nuestra COPREPA, tal y como hemos señalado. En Alemania la idea de la cooperación interparlamentaria se puede categorizar como un instrumento del federalismo cooperativo y del carácter integrador con el que se asocia. Es una cooperación interparlamentaria de carácter orgánico, Conferencia de los presidentes de los parlamentos de los länder, que se apoya en una infraestructura cooperativa funcional, como es la asociación de directores de los parlamentos alemanes, fundada en 1925, lo equivalente a letrados mayores en nuestro contexto, y en la Comunidad de Trabajo Interparlamentario -Die Interparlamentarische Arbeitsgemeinschaft (IPA)- que data de 1953 y cuya singularidad es integrar a aquellos parlamentarios de los Landtag, del Bundestag y del Parlamento Europeo que quieran trabajar activamente en pro de la cooperación interparlamentaria. Como datos de interés de la Landtagspräsidentenkonferenz, LPK, destaca su carácter preconstitucional, ya que data de 1947, con lo que su función trascendió más allá de la cooperación interparlamentaria contribuyendo a forjar un Estado constitucional y federal, sobre una base democrático-parlamentaria, y su composición, en la que integra al presidente del Bundestag y al letrado mayor del Bundesrat. En sus conferencias ha ido abordando, desde un forma ágil y flexible, las principales cuestiones que atañen a los parlamentos federados, a la par que no ha desdeñado posicionarse sobre cuestiones constitucionales, siempre defendiendo su estatus subestatal ${ }^{24}$.

23 El estudio de los casos estadounidense y canadiense se fundamenta en una concepción instrumental del federalismo, en este caso con el apelativo de federalismo legislativo, en la que se prioriza su capacidad de beneficiar a las personas, más allá de un reparto de poder entre instituciones. Estados Unidos es donde se ha definido la idea moderna de gobierno federal (Wheare), siendo indudablemente su principal contribución a la teoría política (Morley). Por lo tanto, es imprescindible recabar cómo sus "inventores" (Derthick, 1992: 10) han afrontado la implementación pionera del federalismo legislativo, referenciándolo como un "modelo" (Scheiber, 2000), que se puede seguir o no, pero del que podemos aprender. Por su parte, en Canadá hallamos un referente inexcusable en la conjunción entre federalismo y parlamentarismo donde la dimensión colaborativa entre instituciones se ha erigido como un signo identitario y singularizante de esa federación, hasta el punto de consolidar un Ministerio de Relaciones Intergubernamentales. Pese a ello, el reto radica en ver qué hay detrás de ese velo referencial de federalismo interestatal (Simmons, 2017: 573), cuando sus protagonistas son los legislativos y cuando su objetivo es alcanzar un federalismo intraestatal - la representación de las unidades subestatales dentro de las instituciones estatales-, la auténtica "cuadratura del círculo" (Smiley y Watts, 1985: 29).

24 Un estudio de la misma puede verse en Huth, Ronald, (1988) Die Konferenz der Präsidenten der deutschen Landesparlamente; eine Studie über ihre Geschichte und Funktion unter besonderer Berücksichtigung ihres Beitrages zur Stärkung landesparlamentarischer Kompetenzen, Frankfurt,WSV, Wirtschafts- u. Sozialpolitik Verl.-GmbH. En castellano, el trabajo de 1987 de Embid Irujo al que hemos hecho referencia. La temática viene a coincidir con la que se ha abordado en su homólogo español (aspectos de funcionamiento de las Cámaras, la relación con el Senado, las comisiones de investigación parlamentaria, el estatuto de los diputados, la relación federación-länder o, recientemente, la digitalización y las oportunidades y retos que plantea para los parlamentos estatales (Declaración de la Conferencia de los Presidentes de Landtag en el Castilllo de Ettersburg, 11 junio de 2018. Si bien hay un dato que nos aproxima al federalismo legislativo que veremos en el caso estadounidense, que convierte a esta Conferencia de Presidentes en impulsores de una legislación común, a adoptar luego por cada Landtag, tanto en el caso de las comisiones de investigación parlamentarias, como en lo relativo al derecho de petición (Embid, 1987: 37). 


\section{ESTADOS UNIDOS}

Las relaciones interestatales en los Estados Unidos han evolucionado de forma paralela al tránsito entre modelos federales. Así, desde un federalismo dual que marcaría la colaboración entre niveles territoriales en términos de mínimos, pasando por su evolución hacia un federalismo cooperativo, donde es difícil concebir la formalización de cualquier política sin la implicación de todos los niveles territoriales, hasta un federalismo coactivo, donde la federación pugna por monopolizar y controlar las actuaciones estatales.

En lo que se refiere a la implementación estadounidense del federalismo legislativo, la inexistencia de instituciones formales que canalicen las relaciones entre el Legislativo federal y los Legislativos estatales, o de estos entre sí, no obsta que podamos hablar de una conexión entre ellos. Las manifestaciones del mismo se circunscriben a los siguientes considerandos, orgánicamente y funcionalmente.

Orgánicamente, desde el punto de vista asociativo puede hablarse de una cooperación interlegislativa. La mayoría de los legislativos estatales participan en asociaciones profesionales como la Conferencia Nacional de Legislativos Estatales, NCSL ${ }^{25}$. $\mathrm{Su}$ principal cometido es asesorar a los legislativos de los Estados a identificar las mejores políticas de sus homólogos y promover la celebración de acuerdos interestatales. Desde esta organización también se canalizan, en lo que sería una fase ascendente de dichas relaciones, las preocupaciones de los legislativos estatales hacia el Congreso federal, de modo que de la misma pudiera derivarse un apelativo de lobby frente al mismo. Esta presión es ejercida en ocasiones de modo particularizado por los legislativos de determinados Estados, como por ejemplo Nueva York o Illinois, que disponen de oficinas permanentes en Washington. Estamos ante una organización de tamaño "macro", acorde al más puro tópico americano. En sus reuniones anuales se dan cita unos 4000 miembros, pudiendo resumir su actividad en torno a los siguientes referentes:

25 Se funda en 1975 sobre la base de tres organizaciones preexistentes que competían por liderar la defensa de los intereses de los legislativos estatales. Estas eran la National Legislative Conference (NLC), creada en 1948 a la sombra del Council of State Governments, por un grupo de directores de agencias de servicios legislativos, es decir profesional, siendo coherentemente sus objetivos, aspectos procesales legislativos, organización y servicios. En 1959, se forma la National Conference of State Legislative Leaders, impulsada por los grandes estados que, buscando eludir el diseño profesional y la afinidad al ejecutivo de la anterior, perseguía en realidad rivalizar con la National Governors Association. A principio de los 60 surge la National Society of State Legislators, impulsada desde el sector privado y que reivindicaba un papel más activo de los legislativos estatales. En esa misma línea, presente en la actual asociación de conexión público-privada, se crea la Citizens Conference on State Legislatures, a principios de los 70, a medio camino entre lobby y sincera preocupación por impulsar el rol de los legislativos estatales. En el bienio 1973-74, el liderazgo de diferentes presidentes de legislativos estatales, especialmente el de Connecticut William Ratchford, y el apoyo académico de la Eagleton Institute of Politics, de la Universidad Rutgers, condujo a la disolución de las dichas asociaciones y la formación de la National Society of State Legislators/Conferencia Nacional de Legislativos Estatales. Véase Kurt, Karl, "Our History" (https://www.ncsl.org/bookstore/state-legislatures-magazine/sl-mag-the-history-of-us.aspx). Su web es muy rica en contenidos https://www.ncsl.org 
- Consultoría, asesoramiento e información a los legislativos estatales. Se convierte en una especie de Consejo que lleva a responder unas 16.000 consultas anuales, tanto de carácter procesal como sustantivo, remitidas por los diferentes miembros (profesionales y representantes) de los legislativos estatales, e incluso a recabar la presencia de expertos para las diferentes comisiones de cada parlamento.

- Proveer una base de datos a los legislativos estatales. A través de la plataforma NCSLnet se facilita el acceso de los miembros de los legislativos estatales a LEGISNET y a los diferentes repositorios temáticos de la NCSL, así como a artículos e investigaciones desarrolladas por la Conferencia y por cada estado.

- Organizar encuentros y seminarios. Una gran conferencia anual, en los meses estivales, a la que se agregan diversos foros, seminarios y con múltiples recursos multimedia, destacando los "webinar", podcasts, vídeos divulgativos y publicaciones. Mensualmente publica una revista, State Legislatures, y trimestralmente, Conference Report, a lo que se agregan diversas publicaciones temáticas de interés para los legislativos estatales.

- Finalmente, podríamos destacar una importante actuación formativa, programa TRAIN, que atiende a las demandas del personal de los parlamentos y a los propios parlamentarios. Es una asociación de composición híbrida, de profesionales y trabajadores de los legislativos y parlamentarios, con un gran activismo en asuntos federales y a través de una fundación que desarrolla una gran tarea de apoyo a los legislativos (Foundation for State Legislators).

El papel de los legislativos estatales en Estados Unidos ha sido objeto de un cada vez mayor protagonismo, sin poder obviar que, salvo Nebraska, todos los estados federados tienen un legislativo bicameral, cuya actividad ha sido reflotada de la mano del nuevo federalismo judicial, que ha descubierto el potencial estatal para defender los derechos de los ciudadanos, y de la búsqueda de un alter al poder de los gobernadores, pese a la naturaleza presidencial del sistema (Seijas, 2019a: 296).

Funcionalmente, la más llamativa implicación de ese federalismo legislativo deriva en la aprobación de leyes uniformes, con lo cual se busca fortalecer los estados, promoviendo su autonomía, a la vez que simplificar la vida de los ciudadanos que bien trabajan o viajan por los distintos estados. La existencia de "leyes uniformes" (Smith, 2015: 418) es consecuencia del acatamiento de las propuestas formuladas por la Uniform Law Commission, ULC, anteriormente designada Con- 
ferencia Nacional de Comisionados sobre Leyes Estatales Uniformes (NCCUSL) ${ }^{26}$, que está integrada por juristas designados por los gobernadores de los estados. Su slogan es Better Laws, Stronger States. En la práctica, estas leyes uniformes no lo son en puridad, dado que no todos los estados las aprueban, y cuando lo hacen, introducen modificaciones en el proceso legislativo. Existen significativas excepciones en que se aproxima a esa uniformidad legislativa, como por ejemplo en materia de comercio, mediante la adopción de un Código Comercial Uniforme, que se aplica a las ventas y transacciones comerciales. Pero ni tan siquiera este texto puede calificarse de uniforme, ya que por ejemplo Louisiana lo ha adaptado a la singularidad de su código civil, de tradición hispano-francesa.

En esa cooperación estatal-federal en el ámbito de los legislativos, fase ascendente, también se ha de integrar la potestad de los legislativos estatales, de dos tercios de ellos, para instar la creación por el Congreso de una Convención Constitucional, con el objetivo de proponer enmiendas a la Constitución de los Estados Unidos. Por otro lado, cualquier propuesta de enmienda o de convocatoria de una Convención por parte del Congreso debe ser ratificada por tres cuartas partes de los legislativos estatales o por Convenciones estatales popularmente elegidas. La colaboración parlamentaria impulsa así uno de los rasgos más característicos de un modelo ideal de federalismo: la participación de los estados en la reforma constitucional.

En una proyección descendente -referida a la colaboración interparlamentaria para la aplicación de la legislación federal en los estados-, cabría sostener que formalmente el Congreso carece de instituciones dedicadas a monitorizar las relaciones intergubernamentales, o conseguir de modo directo que los estados acaten las prescripciones federales, si dejamos de lado la Oficina Presupuestaria del Congreso. No obstante, existen diferentes estrategias por las que el Congreso usa sus poderes constitucionales para canalizar la acción de los estados. Estos supuestos que hacen referencia

26 Esta organización data de 1892, fecha desde la que ha procedido a redactar más de 300 proyectos de leyes uniformes. Diferencia en sus actuaciones entre leyes uniformes, si han sido descritas así a nivel federal, o leyes modelo, cuando pretenden ser el referente de las distintas leyes a adoptar por los legislativos de los estados. El funcionamiento de esta comisión parte de una estructura integrada por el Comité Ejecutivo y el Comité de Alcance y Programa. Unos comités sectoriales de estudio revisan un área de derecho asignada a la luz de criterios definidos y recomiendan si ULC debe proceder a elaborar un borrador sobre ese tema. Unos comités de redacción redactan dichos borradores de leyes uniformes sobre temas específicos. Las ideas para nuevos uniformes o modelos de actos son consideradas por el Comité de Alcance y Programa de ULC, que recibe solicitudes de asociaciones de abogados, entidades gubernamentales estatales, grupos de interés privado, comisionados de derecho de uniformes y ciudadanos privados. Cualquier parte que desee sugerir una idea para un acto uniforme o modelo puede comunicarse con la oficina central de la ULC en Chicago, que enviará la sugerencia al Comité de Alcance y Programa. El iter es el siguiente. Se propone una idea al Comité de Alcance y Progreso. Este lo remite al Comité Ejecutivo. Tras dos años de estudios, se traslada a su consideración por la Conferencia Anual, en la que se vota por los representantes de los estados. Si se aprueba, se derivan a los legislativos estatales donde estos la tramitarán, si lo estiman oportuno y tiene los apoyos para ello, hasta su conversión en una ley formal. Materialmente se centran en derecho comercial, derecho de familia, sucesiones y fideicomisos, bienes raíces o resolución prejudicial de conflictos. Entre las propuestas legislativas más ampliamente adoptadas se encuentran el Código Comercial Uniforme, la Ley Uniforme de Donaciones de Órganos, la Ley Uniforme de Secretos Comerciales, la Ley Uniforme de Jurisdicción y Cumplimiento de la Custodia de los Niños, la Ley Uniforme Interestatal de Apoyo Familiar, la Ley Uniforme de Transacciones Electrónicas, la Ley Uniforme de Transferencias a Menores o la Ley Revisada Uniforme de Acceso Fiduciario a los Activos Digitales. https://www.uniformlaws.org/home 
a la preemption ${ }^{27}$, los mandatos y las órdenes directas ${ }^{28}$, que son en realidad, instrumentos coactivos, más que cooperativos. En el marco del federalismo fiscal, el Congreso desempeña un rol de activador de las políticas estatales en un determinado sentido. Así, a partir del amplio poder de gasto federal, el Congreso puede instar a los estados a adoptar nuevas responsabilidades y desarrollar unas líneas políticas precisas. Esas subvenciones pueden ser generales, por ejemplo, en servicios sociales, o muy específicas y puntuales. El Congreso no puede, como sostuvo el Tribunal Supremo, forzar a los estados a aceptar esas subvenciones, pero si las desean tienen que cumplir con los requisitos marcados en las mismas (South Dakota versus Dole, 483, U.S. 203 (1987). Aquí el espacio para la colaboración interparlamentaria es una apelación a una resistencia a preservar su autonomía, que pugna con una tendencia centralizadora cada vez mayor. Un bloqueo a estas medidas implica renunciar a fuentes de financiación y, por consiguiente, comprometer la calidad de las actuaciones sobre los ciudadanos. La eficacia más directa se desplazaría hacia un federalismo intraestatal donde los representantes de los estados en el Senado frenasen esas prácticas.

El Congreso, a veces, autoriza renunciar a políticas específicas federales a los efectos de fortalecer la experimentación política de los estados y la flexibilidad y cooperación intergubernamental. Curiosamente, se puede percibir un efecto bumerán en estas políticas, dado que si se readoptan como federales, de las mismas pueden derivarse diferentes mandatos a los estados, como aconteció con las reformas sanitarias de Obama (2010), inspiradas en las de Massachussets (2006).

La interpretación que el Tribunal Supremo parece hacer de todas estas prácticas lleva a su concepción como "un lento movimiento hacia la limitación de los poderes del Congreso" y el consiguiente apoyo a la autoridad discrecional de los gobiernos estata$\operatorname{les}^{29}$, y también de sus legislativos. Es por ello que dichas relaciones entre los estados se hayan calificado no de federales, sino de confederales (Hanson, 2008: 31).

27 Esta actuación se describe como el desplazamiento por parte de las leyes federales de las leyes estatales en determinadas circunstancias. La traducción más certera sería la fusión de dos de sus principales significados. Por un lado, la prevalencia de la legislación federal frente a la legislación de las unidades constituyentes estatales. Por otro, la anticipación con que la legislación federal se promulga con respecto a la legislación de los estados. Su materialización se concreta bien en la obstaculización o impedimento por parte de las autoridades federales de prácticas o políticas estatales de corte innovador, o bien de un ejercicio de predominio y superioridad que condicionaría dichas actuaciones (Seijas, 2018: 159-161).

28 El término mandato cubre una amplia tipología de actuaciones políticas con el denominador común de generar efectos centralizadores y coercitivos sobre las políticas públicas y la actividad legisladora de los parlamentos estatales. Estos mandatos serían: legislación que incluye mandatos directos, condiciones para subuenciones, tanto específicas como transuersales, legislación "preeminente" total o parcial, previsiones federales sobre ingresos fiscales que afectan a las bases imponibles estatales o locales, actuaciones legales desarrolladas por los tribunales y agencias federales; normativa sobre demoras y no ejecuciones; habilitación federal para interponer recursos a los gobiernos estatales y locales. Toda esta serie de medidas han concluido en promover una nacionalización y centralización en áreas que tradicionalmente eran un espacio de actuación exclusivamente estatal (Posner, 2008: 306).

29 INFIB versus Sibelius (2012). En relación con la cláusula de comercio, reclamando que la misma tiene unos límites para la Federación. Otro supuesto, de 2013, es Shelby County versus Holder (2013), donde el Tribunal señaló una extralimitación del Congreso al requerir a los estados una preautorización del Departamento de Justicia Federal, con carácter previo a reformar los procesos electorales. 


\section{CANADÁ}

Aun cuando el federalismo ejecutivo aparece fuertemente arraigado en la cultura política federal canadiense, hay que hacerse eco de una tenue revisión del mismo, de la mano del que hemos denominado "federalismo legislativo", merced al cual las asambleas legislativas desarrollarían un papel más activo en el ámbito de las relaciones interprovinciales, apostando por un refuerzo del papel de los comités legislativos, junto a grupos de expertos, en la revisión de los acuerdos (Bakvis, 2009: 256). La ratificación de esta posición la hallamos en la propia jurisprudencia del Tribunal Supremo, desde donde se sostuvo que el parlamento, y el principio de soberanía parlamentaria en el que se sustenta, es el responsable del diseño de los acuerdos intergubernamentales, de modo que aunque el primer ministro adopte un compromiso con las provincias y en ellas se genere una "expectativa legítima" sobre su contenido, solo el parlamento y no el ejecutivo tiene la autoridad para respaldar su contenido (Reference Re. Canada Assistance Plan (B.C.) 1991, de 15 de agosto, FJ. 42).

Las peculiaridades de los legislativos canadienses (Seijas Villadangos, 2018: 143), donde la mayoría de los legislativos provinciales nacieron bicamerales a imagen del vecino americano para luego proceder a disolver su cámara alta o fusionarla con la cámara popular, se singularizan en que incorporan un legislativo que se compone del representante de la Reina en cada una de ellas, designado como subgobernador (Liutenant Governor), y una Asamblea de electos. En Quebec, el legislativo provincial se denomina desde 1982 Parlement du Quebec, mientras que en tres provincias (Nueva Escocia, Isla del Príncipe Eduardo y Terranova) la denominación es Asamblea General. En las restantes provincias recibe la denominación genérica de Legislativo.

Las relaciones oficiales (cooperación orgánica) entre estos parlamentos son limitadas (Massicotte, 2015: 250), y serían prácticamente inexistentes, a no ser por su pertenencia común a las asociaciones internacionales en las que se integran, como la ya referida Asociación Parlamentaria de la Commonwealth/Commonwealth Parliamentary Association (CPA), la Asamblea Parlamentaria de la Francofonía/Assemblée Parlementaire de la Francophonie (APF) o la Confederación Parlamentaria de las Américas/ Parliamentary Conference of the Americas (COPA) ${ }^{30}$. En el marco de esas asociaciones, los funcionarios de alto nivel de los legislativos, como por ejemplo los portavoces o los miembros de las Mesas, se reúnen anualmente. V. gr. Association of Clerks-at-theTable in Canada, the Association of Parliamentary Counsel in Canada, the Association

30 Se creó en 1997 bajo los auspicios de la Conferencia de Legislativos Estatales estadounidense, la Asamblea Nacional de Quebec y la UNALE, La Unión Nacional de Legisladores y Legislativos Estatales de Brasil. En su estructura se integra un grupo de Mujeres Parlamentarias de las Américas (https://www.feminamericas.net/). Esta asociación se pretendía reactivar con su reunión de marzo de 2020 en Puerto Rico, pero la pandemia de la COVID-19 ha frustrado esa iniciativa (http://www.copa.qc.ca/eng/). 
of Legislative Counsel in Canada ${ }^{31}$ o Canadian Association of Parliamentary Administration (CAPA). Es decir, la cooperación interparlamentaria en Canadá, a pesar de ser menor que la intergubernamental, también existe. Entre los temas abordados en la misma, destaca, por ejemplo, el análisis de las resoluciones provinciales cuestionando las actitudes del gobierno federal o cuestiones puntuales, como el izado de la bandera canadiense en dichas asambleas. Este hecho no está impuesto por la legislación federal, pero de facto se realiza en todas las asambleas, con la salvedad de Quebec. En el otro lado, el Legislative que incorpora las banderas de todas las provincias es el de Alberta. En consecuencia, la lectura de esta cooperación deviene de su conversión en una arena para la batalla.

Ahondando en esas técnicas de cooperación, es preciso efectuar una precisión acerca del modelo westminsteriano de parlamento que ha inspirado el parlamentarismo canadiense. Desde la soberanía parlamentaria, se habilita un escaso reducto a dicha dejación de la misma en otras instituciones y en otros parlamentos. En 1951, el Tribunal Supremo estatuyó que sería inconstitucional que un legislativo delegara sus poderes legislativos en otra Cámara, incluso con carácter revocable, por vulnerar la separación de poderes (Attorney General of Nova Scotia v. Attorney General of Canada, [1951] S.C.R. 31). Es decir, este es un límite infranqueable para la cooperación entre legislativos.

No obstante, esta restricción no cerraría la puerta de modo tajante a un acercamiento funcional entre legislativos, desarrollado a través de distintas estrategias, que se adscribirían a la infinita lista de adjetivos con que se acompaña al federalismo, en este caso federalismo colaborativo (Cameron \& Simeon, 2002: 49)

a. La delegación administrativa faculta al legislativo federal o a los legislativos provinciales a delegar potestades administrativas, por ejemplo, en un Consejo regulador. Esta práctica ha sido usada para regular el comercio provincial e intraprovincial (P.E.I. Potato Marketing Board v. Willis [I952] 2 SCR 392).

b. La incorporación de referencias o estándares. Consiste en la adopción por parte de un legislativo de los estándares legales o bases, en la terminología española, de otro orden de gobierno en un ámbito determinado. Estas técnicas facultan a las provincias a implementar un sistema de reconocimiento mutuo interprovincial, una especie de ventanilla única. Esta estrategia se puede ilus-

31 Su función es el asesoramiento independiente sobre problemas comunes en la vida parlamentaria provincial. Los temas han sido esencialmente procesales: como recomendaciones para los impulsores de private bills o leyes particulares; la tramitación legislativa entre la tercera lectura y la sanción real o las peculiaridades de la legislación económica. (Clegg, 1985: 16-17).

32 Este interesante trabajo ahonda en las sui géneris características de las relaciones intergubernamentales en Canadá, que podrían condensarse en una antinomia que deriva de su eficacia y de su fragilidad. Son útiles porque contribuyen a que problemas encallados en el rigorismo institucional se solventen y son frágiles porque dependen de la voluntad de sus actores (diplomacia federal-provincial), al no haber un mandato constitucional que las regule. Entre sus desventajas, destacan los autores, el riesgo de marginar a los parlamentos de la fiscalización de sus contenidos, algo que quedaría resuelto si se abriera ese campo colaborativo a los propios legislativos (pp. 49 y 64). 
trar con el "sistema de pasaporte" diseñado por las comisiones de seguridad de las distintas provincias, que permitía el acceso a los mercados de todas ellas con la certificación validada en una provincia. La alternativa a esa cooperación provincial podría venir de la habilitación federal para crear tal mecanismo regulador, posibilidad frustrada por la negativa de varias provincias, al considerar que con ello se invaden sus techos competenciales (References Securities Act, 20II). Es decir, se lograría lo mismo con la cooperación provincial, pero si es la federación quien lo postula, sería intromisión inconstitucional en las competencias provinciales. Aquí, los medios son tan importantes como el fin.

c. Otra práctica apunta a la posibilidad de que la legislación de un orden de gobierno se elabore condicionalmente a partir de lo establecido por otro. Así, la legislación federal, suspendiendo la total prohibición de una actividad por motivos penales, declina si un legislativo provincial lo habilita expresamente, como ocurrió en los préstamos a corto plazo sobre los salarios, que incorporaban intereses usurarios. Lo que generaría una aplicación asimétrica del Derecho penal, a partir del artículo 347. I (2), del Código Penal canadiense de I985. El cuestionamiento de esta práctica ha venido de diversas provincias, lideradas por Quebec, esgrimiendo que se trata de una invasión federal en su ámbito de competencias, afectando a la exclusividad de sus títulos. Cuando el Tribunal Supremo tuvo ocasión de pronunciarse sobre este particular en I997, manifestó que se trataba de la traducción concurrente del federalismo cooperativo, implementado a través de las relaciones intergubernamentales, opinión prevalente frente a una minoría que los consideraba como una erosión del reparto competencial trazado por la Constitución (R. v. Hydro-Québec [I997] 3 SCR 213).

Es en esta última manifestación donde se han fusionado la colaboración orgánica interparlamentaria y la proyección funcional, de la mano de la intervención de la Uniform Law Conference of Canada, creada en 1918, emulando el referente estadounidense que hemos analizado líneas atrás. Así, se ha buscado la coincidencia de las reuniones de la Association of Parliamentary Counsel in Canada y la Association of Legislative Counsel in Canada, foros de discusión profesional y asesoramiento, con la Uniform Law Conference of Canada, por ejemplo, desde 1984 (Clegg, 1985: 17), pese a la diferente naturaleza de dichas formaciones. Esta última está auspiciada por la Canadian Bar Association, y busca como objetivo primario "promover la uniformidad de la legislación entre provincias y territorios canadienses en materias en las que sea posible y ventajosa” (https://www.ulcc. ca/en/about-us-en-gb-1/history-of-the-conference). Las principales materias han sido el Derecho procesal penal y el mercantil. Es importante considerar que esta organización es independiente de los gobiernos y que tiene una misión esencialmente instrumental de facilitar las relaciones jurídicas en todo el territorio canadiense. A partir de ahí, pueden derivarse esos estándares incorporables en la legislación provincial en lo que les atañe 
competencialmente, puesto que recordemos que, a diferencia de en los Estados Unidos, el artículo 91 de la Constitución canadiense asigna a la federación la regulación del Derecho penal y la regulación del matrimonio y divorcio.

Es en estos ejemplos donde un federalismo interestatal horizontal, que prioriza las relaciones interprovinciales, se enfrenta a un federalismo intraestatal vertical e integrador, en el que una ideal federación desplegaría su gestión en armonía con los intereses provinciales.

\section{LA COOPERACIÓN INTERPARLAMENTARIA, UNA ETAPA EN LA SENDA FEDERAL: EL FEDERALISMO LEGISLATIVO}

El federalismo aporta una fórmula idónea para la estructuración territorial del Estado español al conciliar la necesidad de continuar y profundizar el autogobierno de las regiones y nacionalidades, junto con una imprescindible unidad, sustentada sobre la solidaridad y la defensa de los intereses generales de la totalidad de la ciudadanía. Esa conversión federal, iniciada tímidamente en la transición y en la paradójica negación constitucional del federalismo (art. 145.1 CE), puede seguir dos senderos: uno formal, a través de una reforma constitucional, otro informal como mutación constitucional, mediante un desarrollo legal, en sentido federalizante. El cambio sustantivo radica en el éxito del fortalecimiento de una cultura federal, erigida sobre la inexcusabilidad de la lealtad y la convicción de la idoneidad de sus principios, abrazar el "deseo federal" (Wheare, 1946: 40). La opción que hemos propuesto para ahondar en nuestra federalidad se articula desde un "federalismo resiliente" (Seijas, 2017: 342), un formato que se adapta a nuestras necesidades de contribuir desde la estructura territorial al mantenimiento y mejora del Estado del bienestar -federalismo funcional- y que atienda a los hechos diferenciales existentes -federalismo asimétrico-, pero que se aleje de alojar discriminaciones bajo el velo de la diferencia (disimetrías). Su evolución tiene que canalizarse desde el respeto a la rigidez de sus postulados esenciales (unidad, pluralidad y solidaridad) y la flexibilidad de su adaptación a la especificidad de la situación española.

En ese iter es imprescindible la cooperación de las partes, ya sea la provista por el diseño constitucional, o bien la que se vaya consolidando mediante la eficacia de mecanismos de relación entre instituciones, que se traduzca en unos efectos para el conjunto de la sociedad. La función de integración que ha de proveer cualquier formato federal se alcanza por esta vía cooperativa, dependiendo de su cumplimiento la vitalidad de la federación. El Estado federal promueve la integración de las diferentes entidades territoriales, respetando la diversidad y observando la imprescindible unidad estatal. Las instituciones de un Estado federal y los parlamentos territoriales lo son, no pueden concebirse únicamente como sujetos pasivos, sino sobre todo como "factores del proceso de integración" (Smend, 1985: 179). 
En ese contexto se ubica la presencia imprescindible de los parlamentos territoriales (federalismo legislativo), como agentes activos de la integración, no solo por su participación en los procesos legislativos multinivel (Seijas 2019b), sino a través de la cooperación interparlamentaria, tal y como hemos mostrado en nuestro análisis. Sobre la naturaleza jurídica de esa cooperación, hemos observado su evolución desde el ámbito político hacia la arena jurídica, en su consolidación como principio rector de las relaciones interparlamentarias. Es en ese halo donde puede desplegar todo su potencial, al beneficiarse de la flexibilidad del discurso político, y proyectar su eficacia en la necesidad de que los parlamentos respeten sus decisiones y doten de eficacia los resultados de dicha cooperación.

Los principales atributos de esa cooperación interparlamentaria se desgranarían del modo siguiente:

La cooperación interparlamentaria es garantía del pluralismo territorial y, por consiguiente, de las fórmulas organizativas a través de las que se canaliza su gestión, entre ellas el federalismo. La cooperación no es un freno a la descentralización, sino un ejercicio armónico y racional de la misma. A través de esas conexiones interparlamentarias se impulsa el protagonismo legislativo territorial, a la vez que mediante el intercambio de información y posicionamientos se busca que la gestión del todo sea eficaz y compatible con las necesidades de cada parte. Los parlamentos territoriales afrontan problemáticas comunes $y$, consecuentemente, no caben objeciones razonables a que las soluciones sean también comunicadas. Entender la descentralización como la búsqueda desesperada de la diferencia no se justifica en los paradigmas contemporáneos de sistemas democráticos que priorizan la atención a los ciudadanos. Es más, esa hipertrofia diferenciadora es la principal patología que aboca las federaciones a un fracaso irreversible. Conectar y cooperar no es centralizar, sino racionalizar esfuerzos y respuestas a dificultades particulares, a la par que rentabilizar las ventajas de un federalismo horizontal, frente a las reticencias y dificultades del articulado verticalmente.

La cooperación parlamentaria es un impulso al fortalecimiento de la institución parlamentaria. Las sinergias cooperativas son un antídoto a la desparlamentarización, puesto que sus decisiones se apoyan en la representación del pluralismo territorial que, en ocasiones, se orilla desde los ejecutivos. Esa primacía del principio parlamentario se concilia con la cooperación porque a través de ella no se quiebra ni se cuestiona la soberanía parlamentaria, que otros instrumentos -como el referéndum- parecen obstinados en enfrentar a la soberanía del cuerpo electoral. Que los parlamentos, los parlamentarios y sus profesionales se formen, informen y deliberen en comunidad no merma "el derecho de hacer y deshacer" (Dicey, 1959: 261) que reside en cada asamblea legislativa, sino que lo enriquece por esa comunicación, que contribuye a recuperar la centralidad de los parlamentos en un momento donde preocupa su marginalidad del sistema político. 
La cooperación interparlamentaria contribuye a alcanzar el equilibrio entre unidad y diversidad que caracteriza al federalismo. La colaboración entre parlamentos no es un eslabón a la uniformidad normativa porque, como hemos visto, ni tan siquiera donde se ha buscado de modo expreso se ha materializado como consecuencia de la soberanía de cada parlamento, pero sí hacia una homologación y operatividad de las leyes que se elaboran, que, pese a tener una eficacia acotada espacialmente, trascienden materialmente dicho territorio.

Sobre esta cimentación teórica, los retos principales de la cooperación interparlamentaria en España son diversos y complejos, pudiéndose proyectar en diversos ámbitos de actuación: la iniciativa legislativa de los parlamentos autonómicos ante el Gobierno y el Congreso de los Diputados, especialmente impulsando iniciativas de reforma constitucional (art. 87.2 y 166); el reto de la eficacia en la innovación y de la apertura parlamentaria a los ciudadanos puede afianzarse si se afronta desde una reflexión conjunta, compartiendo experiencias y resultados de las mismas, que es donde se aprecia un mayor cuestionamiento de dicha tendencia; la presencia de los parlamentos ante la jurisdicción constitucional, desde el condicionamiento de su legitimación activa a la afectación a "su propio ámbito de autonomía" (art. 32.2 LOTC). Cabría imprimir una racionalización a esos procesos, pero también pasivamente, focalizando la atención en atender la erradicación de actos y decisiones que violen derechos y libertades en el seno de las asambleas (art. 42 LOTC); la acentuación de la cooperación interparlamentaria en tiempos de crisis, especialmente crisis sanitarias, donde se ha proyectado una minimización de la actuación de los parlamentos autonómicos y desde luego no se ha aplicado el potencial de su cooperación -prácticamente silencio desde COPREPA, parejo a la CALRE, a diferencia de la NCSL, que ha activado toda su infraestructura de recursos en ayuda de los legisladores estatales- compartiendo estrategias o transmitiendo mensajes coherentes con los de otras autonomías a sus respectivos ciudadanos, cuando se ha evidenciado que aquí no vale sectorializar, que el virus es transversal y se comunica sin reparar en fronteras; potenciar la provisión de herramientas y recursos que acentúen la formación de los parlamentarios y de los profesionales, pero especialmente de aquellos que han de tener un mínimo de conocimientos -constitucionales, estatutarios, procedimientos parlamentarios, fiscales, internacionales- más allá de su estudios de origen para desempeñar su función como representantes de los ciudadanos; las relaciones con el derecho de la Unión Europea, tanto en fase ascendente, como descendente, asumiendo los lógicos plazos perentorios, por ejemplo en control de subsidiariedad, y dando una respuesta común, no una fragmentada por cada parlamento, ante la Comisión Mixta para la Unión Europea, con una reforma de la Ley 38/2010, de 20 de diciembre, de modificación de la Ley 8/1994, por la que se regula la Comisión Mixta para la Unión Europea, para reforzar las funciones asignadas a dicha comisión mixta, donde se contemplase de modo expreso la eficacia de una posición de los órganos de cooperación interparlamentaria. 
Todos estos retos podrían sintetizarse en el esfuerzo de la cooperación interparlamentaria en consolidar los logros alcanzados, a la vez que potenciar su protagonismo, más allá de flashes protocolarios, sin olvidar en el viaje de retorno a cada asamblea todo lo compartido, física o virtualmente, con otros parlamentos. Para ello habrá que seguir cambiando y adaptándonos a las nuevas realidades, sin olvidar que "el constitucionalismo es una ciencia de la paz, es una palabra de esperanza y debe estar lista para la reforma y ser responsable" (Häberle, 2018: 13). †

\section{BIBLIOGRAFÍA}

Aranda Áluarez, E. (2017). Parlamento Abierto. Una visión desde los principios de funcionamiento de las cámaras parlamentarias. Revista Española de Derecho Constitucional, (111), 13-43.

Arce Janáriz, A. (2002). Las Regiones Legislativas de la Unión Europea. Asamblea: revista parlamentaria de la Asamblea de Madrid, (7), 3-18. Recuperado de https://dialnet.unirioja.es/serulet/articulo?c odigo $=633169$ \&orden $=0$ \&info $=$ link

Arce Janáriz, A. (2005). La conferencia de asambleas legislativas de las regiones de Europa (CALRE) como ejemplo de colaboración interparlamentaria. En Jornadas sobre los parlamentos y déficit democrático en Europa: El papel de los parlamentos regionales, (pp. 1-35). Zaragoza: Fundación Giménez Abad. Recuperado de https://dialnet.unirioja.es/ descarga/articulo/5771868.pdf

Astarloa Huarte-Mendicoa, I. (1998). Elementos para el desarrollo de la cooperación parlamentaria. Corts. Anuario de Derecho Parlamentario, (6), $113-144$.

Bakuis, H. et al. (2009). Contested federalism. Certainty and ambiguity in the Canadian federation. Ontario: Oxford University Press.
Cabo, D. (2013). Civio y el open data. En I. Ramos Vielba et al. (Coords.). Parlamentos Abiertos a la sociedad. Participación y monitorización. Madrid: Fundación IDEAS - Friedrich Ebert Stiftung.

Cameron, D. y Simeon, R. (2002). Intergovernmental Relations in Canada: The Emergence of Collaborative Federalism. Publius: The Journal of Federalism, 32 (2), 49-72. https://doi.org/10.1093/ oxfordjournals.pubjof.a004947

Campos-Domínguez, E. (2014). Historia, concepto y evolución del Parlamento 2.0. En R. Rubio-Núñez (Coord.). Parlamentos abiertos: tecnología y redes para la democracia, (pp. 31-60). Madrid: Congreso de los Diputados.

Clegg, M. (1985). The Association of Parliamentary Counsel in Canada. Canadian Parliamentary Review, 8 (1), 16-17. Recuperado de http://www. reuparl.ca/english/issue.asp?param $=112$ \&art=450

De la Fuente Cabero, M. I. (2004). El papel de los Parlamentos nacionales en la Unión Europea. Revista parlamentaria de la Asamblea de Madrid, (11), 97-124.

Derthick, M. (1992). The Structural Protections of American Federalism. En H. Scheiber (Ed.). North American and Comparative Federalism: Essays for the 1990s (pp. 2-23). Berkeley: University of California, Institute of Governmental Studies Press 
Dicey, A. (1959). Introduction of the law of the Constitution. Londres: Macmillan, (primera edición 1885).

Embid Irujo, A. (1987). La conferencia de presidentes de parlamentos de los Länder: un ejemplo de federalismo cooperativo y de cooperación interparlamentaria. Revista de las Cortes Generales, (11), 27-46.

Elorriaga Fernández, G. (2001). La diplomacia parlamentaria. Revista de Las Cortes Generales, (54), 7-20. https://doi.org/10.33426/rcg/2001/54/796

Fernández Alles, J. J. (2010). La cooperación interparlamentaria e intergubernamental de las Comunidades Autónomas en asuntos europeos tras la STC 31/2010. Revista de Derecho Político, (79), 61-113.

García Chourio, J. G. (2018). La cooperación parlamentaria internacional en la era de la gobernanza global. Revista de Relaciones Internacionales de la UNAM, (130), 11-51.

García-Escudero Márquez, P. (2015). Regeneración del Parlamento, transparencia y participación ciudadana. Teoría y realidad constitucional, (36), 171-216.

García Vázquez, S. (2018). La cooperación interparlamentaria y el despertar fallido de los parlamentos nacionales: Desequilibrio institucional e impacto de la integración europea sobre las instituciones de los estados miembros. Revista de Derecho Constitucional Europeo, (29). Recuperado de https://www.ugr.es/ redce/REDCE29/articulos/03_GARCIA.htm

Giraldo-Luque, S. et al. (2017). ¿Cómo usan los parlamentos las redes sociales? Un estudio comparado y longitudinal aplicado a países de América y Europa (2010, 2015 y 2017). Revista Latina de Comunicación Social, (72), 1278-1299.

http://dx.doi.org/10.4185/RLCS-2017-1219
Greciet García, E. (2018). Cuarenta años de Parlamentos autonómicos. En B. Pendás García, (Dir.). España constitucional (1978-2018): trayectorias y perspectivas, vol. 4, tomo 4, (pp. 3561-3574). Madrid : Centro de Estudios Políticos y Constitucionales.

Häberle, P. (1996). Retos actuales del Estado Constitucional. Oñati: IVAP.

Häberle, P. (2018). El constitucionalismo como proyecto científico. ReDCE, (29), 1-14.

Hanson, R. (2008). Intergovernmental Relations. En V. Gray y R. Hanson (Eds.). Politics in the American States. A comparative analysis, cap. II. Washington: CQ Press.

Mergel, I. (2013). A framework for interpreting social media interactions in the public sector. Government Information Quarterly, 30 (4), 327 334. https://doi.org/10.1016/j.giq.2013.05.015

Montilla Martos, J. A. (2011). Las relaciones de colaboración en el nuevo marco estatutario: bilateralidad y participación. Revista de Estudios Políticos, (151), 153-199.

Neuhold, C. y Högenauer, A. L. (2016). An information network of officials? Dissecting the role and nature of the network of parliamentary representatives in the European Parliament. The Journal of Legislative Studies, 22 (2), 237-256.

https://doi.org/10.1080/13572334.2016.1163 884

Ordóñez Solís, D. (2000). Las Cortes Generales y los parlamentos autonómicos en la Unión Europea. Revista de las Cortes Generales, (49), 209-256.

Posner, P. (2008). Mandates. The Politics of Coercive Federalism. En T. Conlan y P. Posner. Intergovernmental Management for the $21^{\text {st }}$ Century, pp. 286-307. Washington: Brooking Institution Press. 
Rodríguez-Andrés, R. y Áluarez-Sabalegui, D. (2018). Presencia y actividad de los parlamentos autonómicos en las redes sociales: pocos auances en el fomento de la participación ciudadana. El profesional de la Información, 27 (5), 994-1003.

Rubio-Núñez, R. y Vela-Nauarro-Rubio, R. (2018). El parlamento abierto en España. Revista General de Derecho Constitucional, (27), 1-57.

Ruiz Robledo, A. (2008). La actividad exterior de las Comunidades Autónomas en el segundo estado autonómico. Revista de Derecho Político, (71-72), 481-513.

Scheiber, H. N. (2000). American Federalism as a Model. En K. A. Modeer (Ed). The New Federalism: Structures and Infrastructures. Stockholm: FRN.

Seijas Villadangos, M. E. (2017). Federalismo resiliente: vanguardia y retaguardia de una nueva organización territorial del Estado español. En G. Ruiz-Rico Ruiz (et al.), Regeneración democrática y reforma constitucional (pp. 305-344). Valencia: Tirant lo Blanch.

Seijas Villadangos, M. E. (2018). En Estrategias participativas para la resolución extrajudicial de conflictos territoriales en los Estados compuestos: Estudios comparado (Canadá, Estados Unidos y España). Madrid: INAP.

Seijas Villadangos, M. E. (2019a). Las constituciones de los estados federados; en particular las de los estados norteamericanos. Teoría y Realidad Constitucional, (44), 271-308.

Seijas Villadangos, M. E. (2019b). La reforma de la Constitución y la participación de los parlamentos autonómicos en las leyes de ámbito estatal. En A. L. Sanz Pérez y J. M. Corona Ferrero, (coords.). Parlamentos autonómicos y reforma constitucional (pp. 253-288). Santander: Parlamento de Cantabria.
Simmons, J. (2017). Canadian multilateral intergovernmental institutions and the limits of institutional innouation. Regional \& Federal Studies, 27 (5), 573-596. https://doi.org/10.1080/13597566. 2017.1389725

Smend, R. (1985). Constitución y derecho constitucional. Madrid: Centro de Estudios Constitucionales (traducción de Verfassung und Verfassungsrecht, 1928).

Smiley, D. y Watts, R. (1985). Intrastate federalism in Canada. En Research Report, Royal Commission on the Economic Union and Development Prospects for Canada, vol. 39 (pp. xix -170). Toronto: University of Toronto Press for Supply and Services Canada.

Smith, T. (2015). Intergovernmental relations in the United States in an age of partisanship and executive assertiveness. En J. Poirier (et al.). Intergovernmental Relations in Federal Systems. Comparative Structures and Dynamics (pp. 411-439). Ontario: Oxford University Press/Forum of Federations/ IAFCFS.

Tajadura Tejada, J. (2002). El principio de cooperación en el Estado autonómico: concepto, presupuestos y fines. Anuario jurídico de La Rioja, (8), 73-104.

Wheare, K. (1946). Federal Government. London: Oxford University Press.

Williamson, A. (2013). Directrices para el uso de los medios sociales de comunicación por los parlamentos. Ginebra: Unión Interparlamentaria UIP. 